\title{
LA REFORMA CONSTITUCIONAL DE LA CORONA (UNA PROPUESTA RADICAL Y DIEZ MODERADAS)
}

JOAN OLIVER ARAÚJO 
SUMARIO

1. EL RÉGIMEN JURÍDICO DE LA CORONA EN LA CONSTITUCIÓN ESPAÑOLA DE 1978: UNA SINTÉTICA VISIÓN DE CONJUNTO: 1.1. La instauración de la Monarquía en España. 1.2. La Monarquía parlamentaria como «forma política del Estado español». 1.3. El estatuto personal del Rey. 1.4. Refrendo e irresponsabilidad. 1.5. Las funciones del rey: simbólica, moderadora y arbitral. 1.6. Sucesión, Regencia y Tutela. a) La sucesión en la Corona. b) La Regencia. c) La Tutela regia. 1.7. La Casa del Rey.- 2. EL PROCEDIMIENTO CONSTITUCIONAL PARA LLEVAR A CABO LA REFORMA DE LA CORONA: ALCANCE Y SIGNIFICADO DEL ARTÍCULO $168 \mathrm{CE}$ 2.1. Motivos para la reforma constitucional. 2.2. Una Constitución rígida con dos procedimientos reformadores. 2.3. Fases del procedimiento de reforma agravado. 2.4. La finalidad oculta del procedimiento del artículo $168 \mathrm{CE}$ : la inclusión de una cláusula de intangibilidad encubierta. 2.5. A la búsqueda de una solución razonable.- 3. UNA PROPUESTA DE REFORMA TOTAL: DE LA MONARQUÍA BORBÓNICA A LA TERCERA REPÚBLICA: 3.1. Una Constitución, teóricamente, sin cláusulas de intangibilidad. 3.2. Una Monarquía con respaldo constitucional pero no democrático. 3.3. La superioridad ética y política de la República sobre la Monarquía. 3.4. España, República parlamentaria.- 4. DIEZ PROPUESTAS DE REFORMA PARCIAL. 4.1. La «Monarquía parlamentaria» debe definirse como una "forma de gobierno", no como una «forma de Estado». 4.2. Debe suprimirse la preferencia del varón sobre la mujer en el orden sucesorio. 4.3. Las Cortes deben poder inhabilitar al Rey de forma permanente, al objeto de que su «inviolabilidad» no se convierta en una técnica para eludir la acción de la justicia. 4.4. El refrendo debe extenderse al nombramiento y relevo de los miembros civiles y militares de la Casa del Rey. 4.5. Deben controlarse los gastos del Rey realizados con dinero público. 4.6. Deben fijarse las incompatibilidades de los miembros de la Familia Real en el ámbito económico-privado. 4.7. Debe determinarse de forma inequívoca la autoría (y consiguiente responsabilidad) de los discursos del Rey. 4.8. Es preciso igualar el título y el tratamiento que se otorgan a la esposa del Rey y al marido de la Reina. 4.9. Es necesario fijar los principios básicos del estatuto jurídico del Príncipe de Asturias. 4.10. Deben ampliarse las facultades de las Cortes Generales, para proveer lo que más convenga a los intereses de España, en el supuesto de que se extinguieran todas las líneas llamadas en Derecho.- BIBLIOGRAFÍA BÁSICA. 


\title{
LA REFORMA CONSTITUCIONAL DE LA CORONA (UNA PROPUESTA RADICAL Y DIEZ MODERADAS)
}

\author{
POR \\ JOAN OLIVER ARAUJO \\ Catedrático de Derecho Constitucional \\ Universidad de las Islas Baleares
}

«La verdad es la verdad, dígala Agamenón o su porquero.»

ANTONIO MACHADO

\section{EL RÉGIMEN JURÍDICO DE LA CORONA \\ EN LA CONSTITUCIÓN ESPAÑOLA DE 1978: UNA SINTÉTICA VISIÓN DE CONJUNTO}

\subsection{La instauración de la Monarquía en España}

La Constitución Española de 1978, tras afirmar que la «forma política del Estado español es la Monarquía parlamentaria» (artículo 1.3), dedica a la Corona su título II (artículos 56 a 65). Además, su artículo 57.1 precisa que «la Corona de España es hereditaria en los sucesores de S.M. Don Juan Carlos I de Borbón, legítimo heredero de la dinastía histórica». Con este precepto venía, de alguna manera, a legitimarse al Monarca reinante. No se olvide que, en un 
primer momento, Don Juan Carlos fue Rey sólo y exclusivamente por la expresa voluntad del general Franco, pues en él no concurrían ni la denominada legitimidad dinástica (ya que el legítimo heredero de Alfonso XIII era su tercer hijo varón, Don Juan de Borbón y Battenberg - por renuncia de sus dos hermanos mayores-) ni la legitimidad democrática (pues la Monarquía nunca ha sido ratificada por el pueblo español a través de un referéndum, sino que fue restaurada por un general golpista tras una cruel guerra civil y una dictadura posterior de casi cuarenta años). Sin embargo, por una parte, Don Juan Carlos obtuvo la legitimidad dinástica (cuestión que, realmente, sólo interesa a los monárquicos) gracias a la renuncia de su padre - Don Juan de Borbón- día 14 de mayo de 1977 y, por otra, una cierta legitimidad democrática con la aprobación de la última Constitución Española en diciembre de 1978.

La Monarquía, como indica el profesor Antonio Torres del Moral, «se basa en la familia, en una familia a la que se reconoce el derecho a proveer la persona que ocupa y ejerce la Jefatura de Estado. Esta consecuencia exorbitante del hecho familiar es lo que propicia que la Familia regia excepcione en parte el Derecho de familia vigente en el país». Como afirma el profesor Mariano García Canales, la rúbrica del título II («De la Corona») ya deja entrever la referencia a una cierta despersonalización con respecto al titular circunstancial de la Jefatura del Estado, el Rey. Ahora bien, no puede desconocerse que, en último término, la Monarquía puede tener un elemento emocional, mágico si se quiere, como apuntó Walter Bagehot; sin embargo, para el análisis jurídico, la Corona es una denominación específica de un órgano constitucional (la Jefatura del Estado), cuyo titular se recluta en base al principio hereditario (Ángel Menéndez Rexach y Francisco Fernández Segado).

\subsection{La Monarquía parlamentaria como "forma politica del Estado español»}

El artículo 1.3 de la Constitución afirma «que la forma política del Estado español es la Monarquía parlamentaria». Aunque este precepto ha sido criticado, con razón, por la doctrina, tiene la virtualidad de subrayar que estamos muy lejos de la Monarquía absoluta (propia del Antiguo Régimen), en la que el Rey tenía en sus manos todos los poderes del Estado, y de la Monarquía limitada o constitucional (característica del liberalismo doctrinario del siglo XIX y parte del $\mathrm{XX}$ ), en la que el Rey conservaba el Poder Ejecutivo y compartía, a través del derecho de veto, el Poder Legislativo con el Parlamento. En la Monarquía parlamentaria, como subraya el profesor Luis López Guerra, «Parlamento, Gobierno y jueces se configuran como auténticos centros de poder, mientras que el Rey se 
convierte en una figura casi honorífica (el Rey reina, pero no gobierna)». Enrique Álvarez Conde subraya, acertadamente, que la Monarquía parlamentaria constituye «el último estadio de la evolución histórica de las Monarquías, como consecuencia de la introducción y desarrollo de los principios democráticos». En este modelo, el Rey ya no conserva ningún poder decisorio, pues la dirección del Estado corresponde al Parlamento y, a través de un proceso fiduciario, al Gobierno. De forma aún más explícita, este mismo autor indica que la existencia de una Monarquía parlamentaria comporta, por una parte, la subordinación de ésta a la Constitución y, por otra, que el Rey carece «de cualquier poder de decisión política, pues sus funciones deben ser consideradas siempre como actos debidos y nunca como actos discrecionales». Con este planteamiento, se puede afirmar — como hace el profesor Álvarez Conde- que «Monarquía y democracia no son, en la actualidad y en nuestro país, términos opuestos». Un criterio análogo fue el que expresó, en los debates constituyentes, el diputado socialista Gómez Llorente, al defender la enmienda de su grupo parlamentario a favor de la solución republicana. En efecto, tras subrayar los defectos que, a su entender, presentaba la Monarquía y las ventajas de la República, concluyó su intervención con estas palabras: «Finalmente, señoras y señores diputados, una afirmación que es un serio compromiso. Nosotros aceptamos como válido lo que resulte en este punto del Parlamento constituyente. Si democráticamente se establece la Monarquía, en tanto sea constitucional, nos consideramos compatibles con ella».

\subsection{El estatuto personal del Rey}

El Rey es el Jefe del Estado, símbolo de su unidad y permanencia (artículo 56.1 CE). Ser símbolo del Estado equivale, en palabras de Torres del Moral, «a encarnar la unidad del poder estatal, la unión entre sus órganos». La titularidad de la Corona, como afirma el profesor López Guerra, implica «una serie de consecuencias que afectan al status personal del Rey, no sólo por la atribución de ciertos títulos, así como de ciertas prerrogativas económicas, sino también, y fundamentalmente, por dos características: la irresponsabilidad y la inviolabilidad» (artículo 56.3 CE). De forma más concreta:

- En cuanto a los títulos, la Constitución afirma que el suyo es el de Rey (o Reina) de España y puede utilizar también los demás títulos que, de acuerdo con el Derecho histórico, correspondan a la Corona española (artículo 56.2). Este precepto, que no sufrió ninguna alteración durante el proceso constituyente, ha sido desarrollado por el Real Decreto 1.368/1987, de 6 de noviembre, sobre ré- 
gimen de títulos, tratamientos y honores de la Familia Real y de los Regentes. De conformidad con su artículo 6, el uso de títulos de nobleza pertenecientes a la Casa Real solamente podrá ser autorizado (con carácter graciable, personal y vitalicio) por el Titular de la Corona a los miembros de su Familia. El Rey y la Reina recibirán el tratamiento de «Majestad».

- El Rey, al ser proclamado ante las Cortes Generales, prestará juramento de desempeñar fielmente sus funciones, guardar y hacer guardar la Constitución y las leyes y respetar los derechos de los ciudadanos y de las Comunidades Autónomas. El juramento regio, como subraya Miguel Herrero de Miñón, "pone de manifiesto su compromiso personal e institucional, ante la España que simboliza, en pro de unas instituciones y valores propios de una sociedad abierta». También, con análogo criterio, la Constitución establece que el Príncipe heredero, al alcanzar la mayoría de edad, prestará el mismo juramento que el Monarca, así como el de fidelidad al Rey (en cumplimiento de este mandato, Don Felipe de Borbón y Grecia, primer hijo varón de los actuales Monarcas, prestó juramento ante las Cortes Generales reunidas en sesión conjunta el día 30 de enero de 1986).

- En cuanto a las prerrogativas económicas del Rey, el artículo 65.1 CE afirma que recibe de los presupuestos del Estado una cantidad global para el sostenimiento de su Familia y Casa, y distribuye libremente la misma. «Esta lista civil, configurada diversamente en los distintos ordenamientos, y en los distintos períodos del constitucionalismo español, representa una consignación presupuestaria necesaria, es decir, un crédito que forzosamente ha de incluirse en el presupuesto de cada año: podrá modificarse su cuantía, pero no su existencia» (López Guerra).

- Los dos rasgos que definen de forma más característica el status del Rey son: la irresponsabilidad y la inviolabilidad (en nuestras Constituciones históricas —vg., el artículo 168 de la Constitución de 1812, el artículo 44 de la Constitución de 1837, el artículo 42 de la Constitución de 1845 y el artículo 48 Constitución de 1876 - , se añadía que la persona del Rey era «sagrada»; atributo que, debido a la actual secularización del poder político, ha desaparecido en la Constitución de 1978). Como afirmaba Giambattista Rizzo, normalmente se entiende que la irresponsabilidad se refiere a las funciones ejercidas en el desempeño de su cargo de Jefe del Estado, en tanto que la inviolabilidad vendría a ser un status personal de inmunidad frente a las leyes penales. Luis López Guerra, buscando algún tipo de fundamento a estos privilegios exorbitantes, afirma que la irresponsabilidad política del Rey se justifica por su carácter de símbolo de la unidad y permanencia del Estado y, más concretamente, «por la exigencia de refrendo de los actos del Rey, que supone un traspaso de responsabilidad». Por su 
parte, considera que la «inviolabilidad (entendida como inmunidad penal) no supone, ni mucho menos, una licencia absoluta para violar la ley impunemente».

- Por lo que se refiere a la Reina consorte (que sí será Reina) o al consorte de la Reina (que no será Rey), la Constitución (artículo 58) indica que no podrán asumir funciones constitucionales, salvo lo dispuesto para la Regencia.

\subsection{Refrendo e irresponsabilidad}

El artículo 56.3 CE, después de afirmar que «la persona del Rey es inviolable», añade que «no está sujeta a responsabilidad», precisando que sus actos estarán siempre refrendados en la forma establecida en el artículo 64, careciendo de validez sin dicho refrendo (salvo lo dispuesto en el artículo 65). Dicho con otras palabras, el Rey nunca responde de los actos que realiza como Jefe del Estado y siempre hay alguien (que es quien refrenda: el refrendante) que responde por ellos. Se produce, de hecho, una traslación de la responsabilidad, ya que «de los actos del Rey serán responsables las personas que los refrenden» (art. 64.2 CE).

El refrendo, que garantiza la irresponsabilidad del Monarca, es también el fundamento de su carencia de poder efectivo. Ciertamente, como el Rey no responde tampoco decide, como el Rey no decide tampoco se le puede pedir que responda. En esta misma línea de pensamiento, el profesor Francisco Fernández Segado ha señalado que el refrendo es "fundamentalmente una limitación material del poder regio, en cuanto quien refrenda asume íntegramente la responsabilidad de la legalidad y de la oportunidad del acto». En las Sentencias 5/1987, de 27 de enero, y 8/1987, de 29 de enero, el Tribunal Constitucional delimitó el concepto de refrendo de la siguiente manera: a) los actos del Rey deben ser siempre refrendados, con las excepciones indicadas en los artículos 56.3 y 65 CE (esto es, la distribución de la cantidad global que recibe de los Presupuestos Generales del Estado y el nombramiento y relevo de los miembros civiles y militares de su Casa); b) en ausencia de refrendo, los actos del Monarca no tienen ninguna validez; c) el refrendo debe realizarse en la forma fijada en el artículo 64 de la Constitución; y d) la autoridad refrendante asume, en cada caso, la responsabilidad del acto del Rey. Por todo ello, en nuestro sistema constitucional, serían radicalmente inconstitucionales actitudes como las del Rey Balduino I de los belgas (1990) y del Gran Duque Enrique I de Luxemburgo (2008), que se negaron a sancionar leyes aprobadas por sus respectivos Parlamentos invocando problemas de conciencia (lo que obligó, en el primer caso, a una verdadera acrobacia política — la incapacitación momentánea del Monarca — y, en el segundo, a una 
sustancial rebaja de los poderes del Jefe del Estado — que, en adelante, sólo promulgará, pero no sancionará, las leyes-).

De acuerdo con el artículo 64.1 CE, los actos del Rey serán refrendados por el Presidente del Gobierno y, en su caso, por los Ministros competentes, con tres excepciones en las que el refrendo corresponde al Presidente del Congreso de los Diputados (la propuesta de candidato a Presidente del Gobierno, el nombramiento de Presidente del Gobierno y la disolución de las Cortes por falta de acuerdo para elegir un Presidente del Gobierno). Esta enumeración de sujetos legitimados para refrendar que hace la Constitución es, según el Tribunal Constitucional, un numerus clausus; y, en coherencia con ello, en la ya citada Sentencia 5/1987 estimó inconstitucional la pretensión de que el nombramiento de Lehendakari fuera refrendado por el Presidente del Parlamento vasco. La forma del refrendo suele concretarse en una firma que sigue a la del Monarca en los documentos oficiales (refrendo expreso). Sin embargo, también cabe el refrendo de presencia (o refrendo tácito), que se expresa en el acompañamiento del Presidente del Gobierno o de un Ministro en las visitas oficiales del Rey — dentro o fuera de España—, así como en los actos en los que debe pronunciar discursos o mensajes. Los miembros del Gobierno, con su presencia física junto al Rey, asumen la responsabilidad de lo que éste dice y hace (por ello, el Monarca no puede hacer ningún viaje oficial ni pronunciar discursos sin contar con el asentimiento previo y expreso del Gobierno).

\subsection{Las funciones del Rey: simbólica, moderadora y arbitral}

De acuerdo con el artículo 56.1 CE, el Rey es el Jefe del Estado, símbolo de su unidad y permanencia, arbitra y modera el funcionamiento regular de las instituciones, asume la más alta representación del Estado español en las relaciones internacionales, especialmente con las naciones de su comunidad histórica, y ejerce las funciones que le atribuyen expresamente la Constitución y las leyes. En síntesis, pues, podemos afirmar que el Rey tiene funciones (siempre retóricas, nunca efectivas) de una triple naturaleza: simbólicas, moderadoras y arbitrales. Estas funciones genéricas se llevan a cabo a través de las funciones especificas, las cuales se han concretado, de forma casuística, en los artículos 62 y 63 CE. Siguiendo la exposición del profesor Óscar Alzaga Villaamil, que fue diputado en las Cortes Constituyentes, podemos clasificar estas funciones específicas en base a su relación con los tres poderes clásicos del Estado:

a) Facultades conexas con el Gobierno. Proponer el candidato a Presidente del Gobierno al Congreso de los Diputados (está obligado, de acuerdo con las reglas 
implícitas del sistema parlamentario, a proponer aquel candidato que, a priori, tiene más apoyos en la Cámara) y, si es investido, nombrarlo, así como poner fin a sus funciones en los términos previstos en la Constitución; nombrar y separar a los miembros del Gobierno, a propuesta de su Presidente; ser informado de los asuntos de Estado y presidir, a estos efectos, las sesiones del Consejo de Ministros cuando lo estime oportuno, a petición del Presidente del Gobierno; expedir los decretos (que sólo por el peso de la tradición llamamos "reales decretos») acordados en el Consejo de Ministros; conferir los empleos civiles y militares y conceder los honores y distinciones con arreglo a las leyes; el mando supremo de las Fuerzas Armadas; acreditar a los embajadores y otros representantes diplomáticos y recibir a los representantes extranjeros en España (que están acreditados ante él); convocar a referéndum en los casos previstos en la Constitución; y el Alto Patronazgo de las Reales Academias.

b) Facultades relacionadas con las Cortes Generales. Sancionar y promulgar las leyes en el imperativo plazo de quince días (la sanción es el acto por el cual el Rey se muestra conforme con el contenido de la norma; y la promulgación es una fórmula ritual por la que el Monarca ordena que la norma se incorpore al ordenamiento jurídico y que sea cumplida por las autoridades y los particulares); convocar y disolver las Cortes Generales y convocar elecciones en los términos previstos en la Constitución; manifestar el consentimiento del Estado para obligarse internacionalmente por medio de tratados, de conformidad con la Constitución y las leyes; y, previa autorización de las Cortes Generales, declarar la guerra y hacer la paz.

c) Facultades vinculadas al Poder Judicial. El artículo $117 \mathrm{CE}$, tras afirmar que «la justicia emana del pueblo», añade que «se administra en nombre del Rey por jueces y magistrados integrantes del Poder Judicial». Esta declaración tan altisonante está, sin embargo, vacía de cualquier contenido; es, sin duda, un mero tributo a la historia. Con ella — como afirma el profesor Alzaga Villaamil - se quiere subrayar que «no se dicta justicia en nombre de la oportunidad o del interés político del momento, sino de los altos valores éticos que el Estado asume en forma permanente y que simboliza el Rey». En este tercer bloque también hemos de incluir el nombramiento (que no elección) del Presidente del Tribunal Supremo y del Fiscal General del Estado, y el ejercicio (simbólico) del derecho de gracia con arreglo a la ley (que no podrá autorizar indultos generales).

A pesar de esta amplísima lista de teóricas funciones del Monarca, hay que reiterar — para borrar viejas ideas muy fijadas en el subconsciente colectivoque en nuestro sistema constitucional el Rey no tiene ningún poder real y efectivo (se ha producido, en relación con épocas anteriores, un absoluto vaciado de la ins- 
titución); sus poderes actuales son meramente simbólicos y coreográficos, huérfanos de cualquier contenido. La Corona es un órgano constituido, no un órgano constituyente, ni constituyente constituido, es decir —utilizando las palabras del profesor Solozábal Echavarría-, «sin atribuciones soberanas ni, por tanto, participación efectiva en la actuación legislativa, competencia exclusiva del pueblo o de sus representantes; ni participación alguna en el establecimiento de la dirección política del Estado, ni en su actuación». De hecho, la afirmación realizada, en noviembre de 2008, por un importante político conservador español (Esteban González Pons), en el sentido de que la función de los Reyes tiene mucho parecido a la que se le asigna a la bandera de España, es — desde la óptica constitucional - bastante correcta. El Monarca no decide ninguna cuestión con trascendencia política (ni legisla, ni gobierna, ni juzga) y, por la misma razón, es irresponsable de los errores que puedan producirse. A nuestro juicio, que la Corona sea una institución hueca de contenido político es su mayor garantía de futuro: como no puede decidir, tampoco puede equivocarse (ni, por supuesto, entrar en colisión con el Parlamento, el Gobierno o los tribunales). Walter Bagehot, uno de los grandes teóricos del constitucionalismo británico en el siglo XIX, indicó que - en la Monarquía parlamentaria - la función del Rey se concreta, a lo más, en advertir, animar y aconsejar; es decir, utilizando la conocida expresión de Dicey, se trata de un poder meramente residual. La práctica totalidad de la doctrina - si bien es cierto que con alguna voz discrepanteha entendido que las funciones del Rey (tanto las genéricas como las específicas, que concretan aquéllas) «se desenvuelven en el terreno de la auctoritas, pero no en el de la potestas, entre otras razones porque no es compatible con una moderna Monarquía parlamentaria, que incluye el principio general de la necesidad de refrendo» (Alzaga Villaamil). Estamos, en palabras de Gregorio Peces-Barba, ante una Monarquía «sin poderes propios».

\subsection{Sucesión, Regencia y Tutela}

a) La sucesión en la Corona

La Constitución, como resulta lógico al consagrar una forma de Jefatura de Estado monárquica, establece un criterio automático de sucesión, de manera que en ningún supuesto (excepto en el caso de extinción total de la dinastía) pueda quedar vacante la Corona. En este sentido, como afirmaba el profesor Nicolás Pérez Serrano, «la transmisión de la Corona se efectúa ope legis y en el seno de una familia (dinastía) cuyos miembros ostentan el derecho a ocupar el trono en 
caso de vacante, según el orden al objeto establecido». Así, puede afirmarse, rotundamente, que el sistema sucesorio es la «verdadera almendra» de la institución monárquica (Torres del Moral).

La fórmula sucesoria adoptada por la Constitución de 1978 es la tradicional en España desde la Ley de Partidas de Alfonso X el Sabio de 1265, y ya se había incorporado a todas nuestras Constituciones del siglo XIX. Así, el artículo 57.1 CE, tras referirse a Don Juan Carlos I de Borbón, afirma que «la sucesión en el trono seguirá el orden regular de primogenitura y representación, siendo preferida siempre la línea anterior a las posteriores; en la misma línea, el grado más próximo al más remoto; en el mismo grado, el varón a la mujer, y en el mismo sexo, la persona de más edad a la de menos». Como vemos, el sistema sucesorio se asienta sobre cuatro principios: el principio de preferencia de la línea recta sobre la colateral, el principio de preferencia de los hijos sobre las hijas, el principio cronológico (tienen prioridad los que han nacido primero sobre los que han nacido después) y el principio de representación (los descendientes representan a sus ascendientes directos). También debemos subrayar que los hijos nacidos fuera del matrimonio («ilegítimos» o «naturales», en la antigua terminología) no tienen ningún derecho sucesorio, ya que — de forma arcaica y poco respetuosa con el artículo 14 de la Constitución - se sigue «vinculando matrimonio y legitimidad de la descendencia» (Yolanda Gómez Sánchez). Con la expresión «orden regular», presente ya en el Derecho medieval castellano-leonés, se quería indicar que, «en la sucesión de la Corona, sólo se llamaba a los nacidos por naturaleza de legítimo matrimonio y primero se consideraba la línea, segundo el grado, tercero el sexo y cuarto la edad», citando las palabras reiteradamente utilizadas por los juristas castellanos.

En síntesis, pues, el orden sucesorio establecido en el artículo 57.1 CE «engarza con la regulación de nuestro Derecho histórico, que arranca de la Ley de Partidas, de la costumbre de la Corona de Aragón y del Fuero General de Navarra». Sin embargo, al ser incluidas dichas reglas históricas en la Constitución de 1978, «son, en su definición básica, normas singulares de Derecho Constitucional positivo que regulan la sucesión temporal de los titulares de la jefatura monárquica del Estado, y ello con arreglo a determinados órdenes y preferencias que sirven para identificar en cada momento, y entre varias personas, al heredero al trono» (Consejo de Estado).

Por otra parte, siguiendo con el análisis del Texto de 1978, hay que hacer referencia a dos supuestos de marcado interés constitucional en esta materia. En primer lugar, el caso de inexistencia de sucesor por extinción de todas las líneas llamadas en Derecho. En este supuesto — de acuerdo con el artículo 57.3 CE_, «las Cortes Generales proveerán a la sucesión en la Corona en la forma que más 
convenga a los intereses de España». En segundo lugar, el supuesto de matrimonios inconvenientes para el país. Así, el artículo 57.4 CE afirma que, «aquellas personas que teniendo derecho a la sucesión en el trono contrajeren matrimonio contra la expresa prohibición del Rey y de las Cortes Generales, quedarán excluidas en la sucesión a la Corona por sí y sus descendientes» (remarquemos que, para que se pierdan los derechos sucesorios, es preciso que se hayan producido ambas prohibiciones expresas con anterioridad a la fecha de celebración de la boda). Esta medida cautelar, que supone un cierto límite a la libertad de elección matrimonial si se quieren conservar los derechos dinásticos, tiene, dentro de la lógica monárquica, una razón de ser, pues — como afirma el profesor Joaquín Tomás Villarroya - el «matrimonio de los Reyes ha tenido y tiene una importancia singular». Con evidente perspicacia, el profesor Jorge de Esteban señaló, cuando se discutía en los medios de comunicación cuál sería la mejor opción matrimonial del Príncipe de Asturias, que éste puede casarse "con quien quiera, pero no con cualquiera». Se trata, sin duda, de una opinión prudente, que intenta evitarle a la Monarquía problemas innecesarios, a veces de graves consecuencias para ella misma (basta pensar, para ilustrar lo que acabamos de indicar, las graves dificultades por las que ha pasado la Casa de Windsor a raíz de los desafortunados matrimonios de los hijos de la Reina de Inglaterra).

Los supuestos que abren paso a la sucesión en la Corona son: el fallecimiento del Monarca (la muerte, que iguala a las personas principales con la gente del común, provoca obviamente el cese automático en el ejercicio de las funciones regias), la abdicación (el Rey decide, por las razones que estima oportuno, abandonar la titularidad de la Corona; observemos que sólo el Monarca ejerciente puede «abdicar», en tanto que las personas con derecho a la sucesión en el trono tienen la facultad de «renunciar» a sus derechos) y, a nuestro juicio, la inhabilitación permanente para el ejercicio de su cometido reconocida por las Cortes Generales (de acuerdo con una interpretación lógica del artículo 59.2 CE: por ejemplo, en el supuesto de que el Rey quedara en coma permanente e irreversible a causa de un accidente). Por último, indiquemos que, a tenor del artículo 57.5 $\mathrm{CE}$, las abdicaciones, renuncias y cualquier duda de hecho o de derecho que ocurra en el orden de sucesión a la Corona se resolverán por una ley orgánica.

\section{b) La Regencia}

Como señala la profesora Yolanda Gómez, «la Regencia es una institución típicamente monárquica que cubre situaciones en las que, aun existiendo titular de la Corona, éste no puede ejercer sus funciones, ya sea por minoría de edad, 
incapacidad, ausencia, etc.». Su característica fundamental es, pues, la interinidad. La discusión principal que plantea esta institución se refiere «al número de personas que deben integrarla, ya que ésta puede ser unipersonal o colegiada. La primera Constitución española, la de 1812, establecía una Regencia colegiada (integrada por tres o cinco personas), mientras que la Constitución actual ha optado por la Regencia unipersonal en la generalidad de los casos», aunque también admite en supuestos más excepcionales una de carácter colegiado. De hecho, la Constitución de 1978 ha regulado con gran detalle la institución, siempre provisional, de la Regencia. Esta circunstancia, a juicio del profesor Jorge de Esteban, encuentra su explicación en nuestra historia reciente, en concreto en las largas Regencias durante las minorías de edad de Isabel II y de Alfonso XIII.

La Constitución vigente contempla dos supuestos de Regencia: por minoría de edad del Rey (artículo 59.1 CE) y por inhabilitación del mismo (artículo 59.2 CE). En el primer supuesto, ejercerá la Regencia el padre o la madre del Rey y, en su defecto, el pariente mayor de edad más próximo a sucederle en la Corona, según el orden establecido en la Constitución (dura el tiempo de la minoría de edad del Rey, esto es, hasta que cumple los dieciocho años). En el supuesto de inhabilitación del Rey, entrará a ejercer inmediatamente la Regencia el Príncipe heredero de la Corona, si fuera mayor de edad; si no lo fuese, se procederá de la manera prevista para la Regencia por minoría de edad del Rey, hasta que el Príncipe heredero alcance la mayoría de edad (esta Regencia finalizará por la recuperación, muerte o abdicación del Rey, así como — a nuestro juiciopor el reconocimiento de las Cortes de su incapacidad permanente). Si no hubiera ninguna persona a quien corresponda la Regencia de conformidad con las reglas anteriores, ésta será nombrada por las Cortes Generales (Regencia electiva), y se compondrá de una, tres o cinco personas. Para ejercer la Regencia, por mandato constitucional y siempre en nombre del Rey, es preciso ser español y mayor de edad. Téngase en cuenta que el Regente, que tendrá el tratamiento de «Alteza» (a no ser que le corresponda otro de mayor rango), asume todas las funciones que la Constitución confiere al Monarca, se beneficia de su irresponsabilidad y precisa refrendo en los mismos términos que la Constitución lo exige al Rey (M. Fernández-Fontecha y A. Pérez de Armiñán).

\section{c) La Tutela regia}

En el supuesto de minoría de edad regia, junto a la Regencia, también tiene relevancia constitucional la Tutela del Rey menor (regulada en el artículo 60 CE, 
de modo bastante distinto a la del Código Civil). Así, mientras el Regente ocupa el lugar del Rey-órgano constitucional, el Tutor ocupa el lugar del Rey-padre.

De conformidad con el citado precepto constitucional, será Tutor del Rey menor la persona que en su testamento hubiese nombrado el Rey difunto, siempre que sea mayor de edad y español de nacimiento (fijémonos que el requisito de la nacionalidad es más estricto para ejercer la Tutela que para desempeñar la Regencia). También merece la pena subrayar que, a la hora de determinar quién suplirá en sus funciones de padre al Rey fallecido, la Constitución da prioridad absoluta a la voluntad testamentaria expresada por éste (frente a la designación del Regente que viene fijada ope legis), lo que permite perfectamente que la Tutela regia recaiga en una persona ajena a la Familia Real y a la vida pública (por ejemplo, un amigo o un clérigo de especial confianza del Monarca). Si no lo hubiese nombrado, será Tutor el padre o la madre, mientras permanezcan viudos (por tanto, a contrario sensu, si contraen nuevas nupcias se les retirará de forma automática la tutela del propio hijo, lo que, aunque es una medida políticamente comprensible, no deja de suscitar algunos problemas por lo que se refiere a las relaciones familiares). En su defecto, el Tutor será nombrado por las Cortes Generales. Pero no podrán acumularse los cargos de Regente y de Tutor sino en el padre, madre o ascendientes directos del Rey. El ejercicio de la Tutela es también incompatible con el de todo cargo o representación política. Como señala Antonio Torres del Moral, la Tutela finaliza «con la mayoría de edad del Rey y, aunque la Constitución no habla de ello, no cabe excluir la renuncia del Tutor, admitida por las Cortes, ni su remoción parlamentaria; en ambos casos deben proveer las Cortes conforme a los mismos criterios del artículo 60 antes expuestos».

\subsection{La Casa del Rey}

La Casa del Rey, como instrumento jurídico al servicio de la Corona, se creó mediante el Decreto 2.942/1975, de 25 de noviembre, pocos días después de la muerte del general Franco y tras la coronación de Don Juan Carlos de Borbón como Rey de España (se unificaron para ello las Casas Civil y Militar del anterior Jefe del Estado). Dicha institución fue consagrada, adquiriendo superior rango, en el artículo 65 de la Constitución de 1978; y, en la actualidad, su organización está regulada en el Real Decreto 434/1988, de 6 de mayo. Así, según establece el artículo 2 de esta última norma, la Casa del Rey se organiza en una Jefatura, la Secretaría General, el Cuarto Militar, la Guardia Real y el Servicio de Seguridad. Además, mediante el Real Decreto 657/1990, de 25 de mayo, se 
creó, dependiendo directamente del Jefe de la Casa, una Oficina con cometidos de apoyo, asesoramiento y asistencia inmediata (Luis Vacas García-Alós). Como afirma dicho autor, dentro de esta organización, tiene una importancia muy especial la figura del Jefe de la Casa del Rey (verdadero director de la Administración Real), ya que es el «máximo responsable jurídico de la actuación administrativa en que se articula la Casa del Rey, con todo lo que eso comporta de cara a la eficacia jurídica de su actuación». Es, en palabras de Javier Cremades García, «la figura central de esta organización, lo que fácilmente se acredita con la sola lectura de sus competencias».

La Sentencia del Tribunal Constitucional 112/1984, de 28 de noviembre, tiene especial interés, pues se refiere a la naturaleza jurídica de la Casa del Rey y al estatuto jurídico de sus miembros. En concreto, dicha Sentencia afirma que «es una organización estatal, pero que no se inserta en ninguna de las Administraciones Públicas». Con análogo criterio se pronuncia el profesor Martín Bassols Coma, cuando afirma que la Corona «requiere una apoyatura administrativa autónoma para el cumplimiento de sus funciones constitucionales», que es precisamente la que le proporciona la Casa del Rey. En la misma línea, el profesor Aurelio Guaita Martorell se inclina por considerar la Casa del Rey como un poder público. De forma más precisa, Luis Vacas García-Alós subraya que la Casa del Rey es una "Administración medial» (un medio para conseguir un fin), "en el sentido de que tanto su naturaleza como su finalidad y fundamento se concentran en su carácter de servicio y de apoyo al órgano en el que se encuentran incardinadas - en nuestro caso, la Jefatura del Estado- y en la ausencia de finalidades generales y directas al servicio de los ciudadanos, a diferencia de lo que sucede con las Administraciones Públicas de base territorial e institucional».

Por otra parte, el Tribunal Constitucional, en la citada Sentencia 112/1984, indicó que los actos que proceden de los órganos a los que se encomienda la gestión de dicha Casa pueden someterse al control jurisdiccional, a través de la vía contencioso-administrativa, y, en el caso de que se aprecie la violación de un derecho o libertad fundamental, tener acceso al recurso de amparo constitucional. El presupuesto jurídico para la existencia de un control jurisdiccional de la actuación de la Casa del Rey es, como señala Luis Vacas García-Alós, «la fuerza expansiva del Estado de Derecho" y el derecho a la tutela judicial efectiva garantizado constitucionalmente. Como afirma el profesor Jesús González Pérez, «en un Estado de Derecho es inconcebible cualquier exclusión en razón de la materia o en razón de la persona. Ni materias excluidas ni personas inmunes al control judicial. Todo acto sujeto al Ordenamiento jurídico, toda actividad ordenada por el Derecho, está sujeto al control de los jueces y tribunales». 


\section{EL PROCEDIMIENTO CONSTITUCIONAL PARA LLEVAR A CABO LA REFORMA DE LA CORONA: ALCANCE Y SIGNIFICADO DEL ARTÍCULO 168 CE}

\subsection{Motivos para la reforma constitucional}

La Constitución - al ser la norma suprema del Estado, que garantiza los derechos y libertades de los ciudadanos y que divide y organiza los poderes - tiene vocación de permanencia y estabilidad. Sin embargo, permanencia no es inmutabilidad. Los Textos Constitucionales son redactados en un concreto momento histórico y, a lo sumo, pueden regular la realidad socio-política existente al tiempo de su aparición. Pero el Derecho, como subraya el profesor Torres del Moral, «envejece, se anquilosa, queda insuficiente y deficiente, caduca ante la nueva realidad social y política. Necesita del poder para renovarse e institucionalizar nuevas ideas y valores». Las causas que pueden convertir una Constitución en un texto anacrónico e insatisfactorio pueden ser de dos tipos: razones socio-políticas, es decir, transformaciones en las condiciones imperantes en un Estado (cambio en las concepciones ideológicas, en las creencias religiosas, en los parámetros morales, en la correlación de fuerzas políticas, en el reparto de la riqueza, en la estratificación social, etc.); y razones de orden técnico, que se concretan básicamente en la aparición de lagunas e imperfecciones no detectadas por el constituyente y que, sin embargo, el dinamismo político se ha encargado de poner de relieve. Pues bien, este necesario ajuste de la Constitución, por motivos socio-políticos o técnicos, puede operarse a través de la reforma constitucional, que implica un cambio en el texto escrito (añadiendo, suprimiendo o alterando algún precepto).

La idea de que la Constitución, como toda norma humana, es modificable y perfectible ya se plasmó en los textos que se aprobaron a finales del siglo XVIII. Así, el famoso artículo 28 de la Constitución Francesa de 1973 afirmaba que: «Un pueblo siempre tiene el derecho de revisar, de reformar y de cambiar una Constitución. Una generación no puede sujetar a sus leyes a las generaciones futuras». Dicho con palabras de Jorge de Esteban, «las generaciones actuales, las nacidas en democracia, tienen el derecho a coparticipar en el pacto político-social que representa la Constitución, a través de su reforma y puesta al día, porque las normas también envejecen y requieren adaptarse a una realidad en perpetua evolución. Sólo así se puede afirmar la superioridad de la Constitución, porque de lo contrario una norma anquilosada ni sería de todos ni sería tampoco eficaz». La Constitución refleja el equilibrio de fuerzas existente al tiempo de su redacción, el statu quo de aquel momento, pero, como ya hemos señalado, la realidad 
está en continuo e inexorable dinamismo y —en este sentido- el procedimiento de reforma es el instrumento idóneo para adecuar el texto de la Constitución a esa realidad sociopolítica cambiante y a las necesidades técnicas que su aplicación haya puesto de manifiesto. De hecho, sólo las Constituciones que se reforman consiguen sobrevivir al paso del tiempo. Recordemos, a modo de ejemplo paradigmático, que, si la democracia norteamericana aún se rige por la Constitución de 1787, se debe a que las sucesivas generaciones, mediante las necesarias revisiones para ponerla al día (veintisiete hasta este momento), la han adaptado a sus concretas necesidades históricas.

\subsection{Una Constitución rígida con dos procedimientos reformadores}

Como es sabido, Lord James Bryce clasificó las Constituciones, atendiendo a su dificultad de reforma, en flexibles y rígidas. Las primeras son aquellas que pueden modificarse siguiendo el procedimiento legislativo ordinario (por ejemplo, las Constituciones del Reino Unido y de Nueva Zelanda); en tanto que las segundas son las que exigen para su revisión requisitos más difíciles de cumplir, por ejemplo, mayorías cualificadas, aprobación reiterada del mismo texto en diferentes legislaturas, referéndum popular, aprobación sucesiva por el Parlamento de la Federación y por los Parlamentos de los Estados-miembros, etc. Las Constituciones rígidas, en sus diferentes modalidades (la rigidez, a diferencia de la flexibilidad, admite una gradación de la misma), son la inmensa mayoría en el panorama del Derecho Constitucional comparado.

La Constitución Española de 1978 es toda ella rígida, es decir, su reforma requiere el cumplimiento de unos requisitos más exigentes que los que se demandan para aprobar las leyes ordinarias (título $X$, artículos 166 a 169). Pero, además, tiene unas partes de la misma especialmente protegidas, cuya reforma es en extremo difícil. Así, el artículo 167 CE contiene el denominado por la doctrina procedimiento de reforma ordinario, que se utiliza para las reformas parciales no esenciales de la Constitución (por esta vía se llevó a cabo la alteración del artículo 13.2 CE, publicada en el $B O E$ el 28 de agosto de 1992). Por su parte, el artículo $168 \mathrm{CE}$ regula el procedimiento de reforma agravado, que deberá seguirse cuando se proponga una revisión total de la Constitución o una parcial que afecte a una de estas tres partes de la misma: el título preliminar (artículos 1 a 9), que contiene la mayoría de las decisiones políticas fundamentales de nuestro sistema constitucional; la sección primera del capítulo segundo del título primero (artículos 15 a 29), que consagra los derechos fundamentales y las libertades públicas; y el título II (artículos 56 a 65), dedicado a regular la Corona. Por tanto, 
desde un punto de vista jurídico y al margen de consideraciones políticas, es tan difícil modificar un precepto cualquiera de estas tres partes como aprobar una nueva Constitución.

El Anteproyecto de Constitución no incorporaba ningún precepto similar al actual artículo 168 (para las reformas totales o parciales esenciales), sino que se establecía un único procedimiento reformador (el del actual artículo 167). «Fue un voto particular, presentado por el Grupo de Alianza Popular, el que motivó su introducción». En base al mismo, la Ponencia constitucional, en su Informe (BOC de 17 de abril de 1978), incorporó en el articulado del Proyecto de Constitución este nuevo procedimiento de reforma. En los debates que se sucedieron en la Comisión de Asuntos Constitucionales, la existencia de dos procedimientos de reforma constitucional fue defendida por el diputado Fraga Iribarne, del Grupo Parlamentario de Alianza Popular; en tanto que el diputado Virgilio Zapatero, del Grupo Parlamentario Socialista, se mostró contrario a la incorporación de este procedimiento agravado para las reformas más sustanciales. Sin embargo, con el apoyo de la Unión de Centro Democrático a la propuesta de Alianza Popular, el Pleno del Congreso de los Diputados aprobó el Proyecto constitucional que consagraba la dualidad de procedimientos de reforma. Acto seguido, el Proyecto pasó al Senado, al objeto de seguir el trámite parlamentario establecido. En dicha Cámara, «el Grupo Socialista y el de Progresistas y Socialistas Independientes presentaron sendas enmiendas, abogando por la supresión» del actual artículo 168, «al entender preferible la existencia de un único procedimiento de reforma». Sin embargo, «ninguna de ellas fue aceptada y el artículo se mantuvo inalterado, pasando así a constituir el definitivo 168» (Santaolalla López).

\subsection{Fases del procedimiento de reforma agravado}

El procedimiento de reforma agravado, que como acabamos de ver protege todos los preceptos constitucionales que se refieren a la Corona, se desarrollaría pues hasta el día de hoy nunca se ha puesto en marcha- siguiendo las fases que se indican a continuación (artículos 166 y 168 CE, 147 del Reglamento del Congreso de los Diputados, 158 y 159 del Reglamento del Senado y 7 de la Ley reguladora de las distintas modalidades de referéndum):

$\left.1^{a}\right)$ Se inicia con un proyecto de revisión constitucional (presentado por el Gobierno) o con una proposición de reforma constitucional (presentada por dos grupos parlamentarios o una quinta parte de los diputados —si se inicia en el 
Congreso- - por cincuenta senadores que no pertenezcan al mismo grupo parlamentario — si se origina en la Cámara Alta—, o por un Parlamento autonómico — que podrá solicitar al Gobierno del Estado la adopción de un proyecto o remitir a la Mesa del Congreso una proposición de reforma constitucional). El proyecto o proposición presentado será sometido a un debate ante el Pleno del Congreso de los Diputados, que se ajustará a las normas previstas para los de totalidad. Terminado el debate, se procederá a la votación. Si votan a favor del «principio de reforma constitucional» las dos terceras partes de los miembros del Congreso, su Presidente lo comunicará al del Senado. Si en esta Cámara recibiera también la mayoría de las dos terceras partes de los senadores, el Presidente del Congreso lo comunicará al del Gobierno para que se someta a la sanción del Rey el Real Decreto de disolución de las Cortes Generales. Por tanto, en síntesis, cuando se proponga una revisión total de la Constitución o una parcial que afecte alguno de los artículos especialmente protegidos, se procederá a la aprobación del principio de revisión por mayoría de dos tercios (esto es, un 66'66 por ciento) de los miembros cada Cámara y a la disolución inmediata de las Cortes. Conviene subrayar, antes de seguir con las fases de este procedimiento, que lo que el primer Parlamento ha de aprobar no es el texto de la reforma, sino el denominado "principio de reforma» o "principio de revisión», cuya concreción ha provocado importantes debates en la doctrina. A juicio de Fernando Santaolalla, que nosotros compartimos, «esta aprobación de principio debe significar una manifestación sobre su oportunidad o directrices, pero no un enjuiciamiento de los concretos preceptos propuestos en la iniciativa de reforma. Todo lo que exceda de emitir un juicio sobre la totalidad corresponde a las Cortes que, en su caso, deben elegirse posteriormente, ya que el apartado 2 determina que son éstas las que deben proceder al estudio del nuevo texto constitucional». Se trata, en consecuencia, de una especie de toma en consideración. Con criterio análogo, el Consejo de Estado, en su Informe de 16 de febrero de 2006, afirma que la interpretación más adecuada «es la que asigna a la primera legislatura la tarea de establecer las razones de la reforma, delimitar su ámbito y precisar su alcance, habilitando en consecuencia a la legislatura siguiente para actuar como legislatura constituyente dentro de esos límites concretos».

$2^{a}$ ) La disolución anticipada del Parlamento trae, como primera consecuencia, que los diputados y los senadores perderán ope legis sus escaños. Esta disposición constitucional tiene una clara voluntad desalentadora de la reforma tanto para el Gobierno en su conjunto como para los diputados y los senadores individualmente considerados, porque tanto aquél como éstos verán como su mandato se ve reducido, sin garantía de repetirlo en el futuro. Tras la disolución del Parlamento, y después de una campaña electoral en la cual la reforma cons- 
titucional estará lógicamente muy presente, se celebrarán elecciones generales.

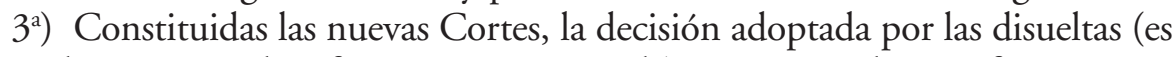
decir, el "principio de reforma constitucional») será sometida a ratificación por el nuevo Congreso de los Diputados. Si el acuerdo de la Cámara Baja fuera favorable al mismo (entendemos que basta la mayoría simple, al no preverse, ni en la Constitución ni en el Reglamento de esta Cámara, nada al respecto), se comunicará al Presidente del Senado. La nueva Cámara Alta que haya resultado elegida deberá ratificar, por mayoría absoluta de sus miembros (así lo prevé el artículo 159 del Reglamento del Senado, lo que ha planteado dudas sobre su compatibilidad con el artículo 79.2 in fine $\mathrm{CE}$ ), aquel principio de revisión constitucional. Por tanto, el primer trámite que deben cumplir las nuevas Cortes es ratificar la decisión de reformar toda la Constitución o alguno de los preceptos especialmente protegidos.

$\left.4^{a}\right)$ Una vez ratificado el acuerdo por ambas Cámaras, el Congreso, por el procedimiento legislativo común, tramitará el «nuevo texto constitucional», que para ser aprobado requerirá la votación favorable de las dos terceras partes de los miembros del Congreso. De obtenerse dicha aprobación, se remitirá al Senado. En esta Cámara, la reforma también requerirá el voto favorable de dos tercios del número de senadores en una votación final sobre el conjunto del texto. Por tanto, dicha propuesta de reforma constitucional (que pretende cambiar, suprimir o añadir algo en el articulado original) también deberá ser aprobada por mayoría de dos tercios (un 66'66 por ciento, recordamos) del Congreso de los Diputados y del Senado.

$5^{a}$ ) Cumplidos satisfactoriamente todos los trámites anteriores, la reforma aprobada por el Parlamento será sometida a referéndum popular para su ratificación, siendo necesario el apoyo de la mayoría de los votos válidamente emitidos en él. Por tanto, el procedimiento que prevé el artículo 168 CE debe concluir, de forma preceptiva, con una consulta popular de ratificación. Se trata, como vemos, de un referéndum de carácter obligatorio, que tiene lugar ope legis, por mandato constitucional, sin que sea preciso que algún órgano o fracción de órgano solicite su convocatoria. Es precisamente este requisito el que más preocupa a los monárquicos cuando se plantea la posibilidad de una reforma constitucional que afecte a algún aspecto de la Corona, pues temen que la campaña previa a la consulta popular y el propio referéndum puedan adquirir un cariz plebiscitario, cuestionando la propia Monarquía como forma de Jefatura de Estado.

En resumen, pues, para reformar una sola palabra de los artículos de la Constitución que se refieren a la Corona hace falta la mayoría de dos tercios en el Congreso y en el Senado, la disolución inmediata de las Cortes (por tanto, 
con pérdida de sus escaños de todos los parlamentarios), nuevas elecciones generales, ratificación de la voluntad de reforma por las dos nuevas Cámaras (por mayoría simple en el Congreso y mayoría absoluta en el Senado), aprobación del texto de reforma por dos tercios en el Congreso y en el Senado y, finalmente, referéndum afirmativo entre todo el cuerpo electoral.

\subsection{La finalidad oculta del procedimiento del artículo 168 CE: la inclusión de una cláusula de intangibilidad encubierta}

El incumplimiento de uno solo de estos requisitos o de cualquiera de estas mayorías, al primer intento, frustra totalmente y sin posibilidad de subsanación la propuesta reformadora. Es, por tanto, evidente - como afirma el profesor Jorge de Esteban- que, más que un procedimiento ideado para utilizarse alguna vez, es un conjunto de obstáculos pensados con el objetivo de que nunca lleguen a aplicarse $\mathrm{o}$, dicho con otras palabras, para que sea un procedimiento de reforma «inviable». Para comprobarlo basta que reflexionemos en lo poco coherente que supone exigir la ratificación de la reforma constitucional por un Parlamento recién elegido, precisamente a causa de que se ha iniciado dicha reforma, y que, inmediatamente después de la aprobación del texto por las nuevas Cortes, también deba convocarse un referéndum de ratificación. Así, aunque resulta lógico y encomiable que se involucre al cuerpo electoral siempre que se quiera reformar algún aspecto fundamental de la Constitución, creemos que la suma de elecciones obligatorias más referéndum preceptivo no responde tanto a una voluntad democrática, como al deseo de entorpecer todo lo posible una reforma de las partes súper protegidas de la Constitución. En efecto, la campaña electoral, motivada por la reforma constitucional iniciada, tendrá como uno de los puntos centrales de la misma «la conveniencia o la inoportunidad de la revisión». En consecuencia, «si ésta resulta nuevamente aprobada por el Parlamento, es porque los electores han dado su visto bueno a la iniciativa de reforma constitucional, otorgando su voto a los partidos que la defienden; de esta manera, la exigencia adicional de un referéndum posterior fijada en el artículo 168 resulta superflua y se convierte exclusivamente en un obstáculo más para desalentar el proceso revisionista» (Joaquín Tomás Villarroya).

A nuestro juicio, los partidos conservadores con mayoría en las Cortes Constituyentes de 1978 no se atrevieron a afirmar que la Monarquía, como forma de Jefatura de Estado, es inmodificable, como en cambio sí que lo hacen expresamente - en relación con la forma republicana - las Constituciones de Francia («La forma republicana de Gobierno no podrá ser objeto de revisión»: 
artículo 89, in fine), Italia («La forma republicana no puede ser objeto de revisión constitucional»: artículo 139), Portugal («Las leyes de revisión constitucional tendrán que respetar:... b) la forma republicana de Gobierno»: artículo 288.1) y Alemania (artículo 79.3 en relación con el 20.1). Ello es así porque, en el fondo, eran conscientes de que - por muy útil que pudiera ser en nuestro contexto histórico - las Monarquías son una anormalidad democrática, que el viento de la historia va eliminado sin vuelta atrás (la misma Presidencia del Gobierno de la República de Bulgaria por el ex Rey Simeón es una muestra paradigmática de que, con independencia de la valía subjetiva de las personas que puedan ocupar el oficio de Rey, la República es, en esencia, la única forma racional y democrática de Jefatura de Estado). Sin embargo, a través de la inclusión de la Corona en el ámbito protegido por el artículo 168 CE, la Unión de Centro Democrático y Alianza Popular pretendieron introducir una cláusula de intangibilidad encubierta, pues sabían que, sin sus votos, las fuerzas progresistas del Parlamento nunca conseguirían los dos tercios exigidos en cuatro votaciones sucesivas (dos en el Congreso y dos en el Senado). Con la misma intención se otorgó al Senado, una Cámara vacía de poderes importantes en la vida política ordinaria, un muy relevante papel en el procedimiento de reforma constitucional del artículo 168, pues dichas fuerzas conservadoras pensaban —erróneamente- que, aunque podrían perder el control del Congreso de los Diputados —en donde el número de escaños por provincias es, más o menos, proporcional a su población-, siempre mantendrían la mayoría en el Senado, pues la España rural y menos desarrollada (que es la que aporta el mayor número de senadores) siempre les daría su apoyo mayoritario. No es de extrañar, en consecuencia, que algún autor se haya referido al «blindaje constitucional» que protege al Rey y a la institución monárquica en su conjunto.

Puede afirmarse, en coherencia con lo anterior, que, en el origen del artículo 168, está el deseo de la mayoría conservadora de las Cortes Constituyentes de dar a la Corona una ultra protección, pues pensaba que, al llegar la izquierda al Gobierno de España, lo primero que intentaría sería cambiar la forma de Jefatura de Estado, por lo que era preciso rodearla de unas garantías extremas. Precisamente por ello, no se dieron semejantes garantías a los otros órganos constitucionales, de mayor importancia — sin duda - que la propia Corona, como son las Cortes, el Gobierno, el Poder Judicial y el Tribunal Constitucional. Por tanto, desde un punto de vista jurídico, podemos afirmar que esta súper protección de la Corona está huérfana de apoyatura lógica y coherente.

Con la actual redacción de la Constitución, y en concreto a tenor de las mayorías exigidas, sin el pleno acuerdo entre el Partido Socialista Obrero Español y el Partido Popular no hay ninguna posibilidad de sacar adelante una reforma 
constitucional de la Corona, lo cual — hoy por hoy— limita las reformas de este órgano a las de carácter exclusivamente técnico o a las muy pactadas (vg., la supresión de la preferencia del varón sobre la mujer en el orden sucesorio a la Corona). Por el contrario, resulta altamente improbable que los partidos conservadores españoles se muestren favorables a restringir aún más los cometidos del Monarca o a controlar de forma más eficaz su actuación, y, muchos menos, que estén de acuerdo en su substitución por una Jefatura de Estado republicana.

\subsection{A la buisqueda de una solución razonable}

A tenor de lo anterior, podemos afirmar que el procedimiento de reforma agravado (artículo $168 \mathrm{CE}$ ) parece un baluarte casi infranqueable, construido para defender la Corona frente a eventuales embestidas republicanas. Sin embargo, como ocurre tantas veces en la vida, no todo está «atado y bien atado». En efecto, como se ha encargado de poner de relieve parte de la doctrina, el artículo 168 CE no está protegido por sí mismo (su amparo sólo alcanza, como hemos visto, a los artículos 1-9, 15-29 y 56-65). En consecuencia, el artículo 168 podría suprimirse por la vía del artículo 167 (procedimiento de reforma ordinario) y, a continuación, ya podría reformarse la Corona siguiendo los trámites, más razonables, establecidos en este último precepto, que regularía ahora el único iter de reforma constitucional.

$\mathrm{Al}$ margen de los procedimientos de reforma constitucional consagrados en el título X de la Constitución, cabría plantearnos ahora la siguiente hipótesis: ¿Qué ocurriría si el Congreso de los Diputados y el Senado, a través de sendas proposiciones no de ley aprobadas mayoritariamente, manifestaran solemnemente su deseo de que España se transformara en una República? Se trataría, sin duda, de unas declaraciones carentes de efectos jurídicos, pero de indudable trascendencia política, pues — no lo olvidemos — las Cortes Generales «representan al pueblo español» (artículo 66.1 CE). De hecho, aunque es obvio que nos movemos en el campo de la especulación teórica, tenemos fuertes dudas de que, en la hipótesis indicada, la Monarquía española pudiera mantenerse en pie mucho tiempo. En el fondo, no puede desconocerse que esta institución tiene, a causa de su origen no democrático, los pies de barro. Recordemos, en este sentido, que la caída de Alfonso XIII y la proclamación de la Segunda República en 1931 tuvieron su causa inmediata en unas modesta elecciones municipales, que en la inmensa mayoría de las capitales de provincia resultaron contrarias a las candidaturas monárquicas. 


\section{UNA PROPUESTA DE REFORMA TOTAL: DE LA MONARQUÍA BORBÓNICA A LA TERCERA REPÚBLICA}

\subsection{Una Constitución, teóricamente, sin cláusulas de intangibilidad}

Como hemos visto, la Constitución Española de 1978 es toda ella rígida. Pero, además, tiene unas partes de la misma especialmente protegidas, cuya reforma es muy difícil. Sin embargo, y tal vez para compensar lo anterior, no contiene - a diferencia, entre otras, de las Constituciones francesa, alemana, italiana y portuguesa - cláusulas de intangibilidad, es decir, declaraciones de que ciertos preceptos de la misma son irreformables. Por tanto, en nuestra Constitución no hay, al menos a nivel teórico, preceptos que se declaren total o parcialmente inmodificables. Utilizando las palabras del Consejo de Estado, podemos afirmar que el poder de reforma constitucional «es plenamente dueño» del contenido de la Constitución, sin limitaciones externas de ningún tipo, y puede, por tanto, alterarla libremente siguiendo los procedimientos establecidos en su título X. En consecuencia, toda la Constitución es susceptible de cambio, y la pretensión de modificarla, incluso radicalmente, encuentra indudable apoyatura en su propio texto.

En este sentido, y por lo que a nosotros nos interesa en estos momentos, hay que afirmar que tanto la definición de la forma política del Estado español como «Monarquía parlamentaria» (artículo 1.3 CE) como el título II, dedicado a la Corona, pueden ser totalmente modificados siguiendo el procedimiento establecido en el artículo $168 \mathrm{CE}$, que acabamos de analizar. Como subraya el profesor Enrique Gimbernat, «es obvio que la sustitución del actual régimen por otro republicano es una idea que puede defenderse con toda legitimidad dentro del vigente marco legal». En la misma línea de pensamiento, el magistrado de la Audiencia Nacional Ramón Sáez de Valcárcel, en un excelente Voto Particular discrepante a la Sentencia de 6 de diciembre de 2008 — que condena a unos jóvenes catalanes por quemar una foto de los Reyes—, afirma lo siguiente: «Los acusados llevaron a cabo, en el contexto de una manifestación de protesta contra la visita de los Reyes a la ciudad de Girona, un acto de crítica política a la forma de gobierno (...). Esa opinión cuestiona instituciones básicas de nuestro sistema - la Monarquía como forma del Estado, su carácter hereditario como fuente de poder (...) — y goza de amparo jurídico en un sistema democrático, que se sostiene por el pluralismo y la libre confrontación de ideas en una opinión pública madura, precondición de la noción de democracia. La conducta objeto de condena — sigue afirmando el Voto Particular- es expresión de una disidencia política, por lo que su sanción penal compromete derechos humanos fun- 
damentales, como la libertad ideológica y la libertad de expresar opiniones, libertades reconocidas en los artículos 16.1 y 20.1.a) de nuestra Constitución. Las peculiaridades del acto público y colectivo de protesta — manifestación en la vía pública, quema de una foto institucional del Rey y la Reina, colocación de la imagen con el pie arriba, los autores iban embozados - no lo excluyen del ámbito de lo permitido en una sociedad democrática, que pretende respetar y proteger la crítica a las instituciones, porque dicha crítica realiza los valores superiores de la libertad y el pluralismo (artículo 1.1. CE). (...) Prender fuego a banderas, símbolos, fotografías o representaciones iconográficas del poder en manifestaciones callejeras es un hecho normal en nuestro mundo globalizado, una manera de exteriorizar un rechazo radical (...) de expresión de disconformidad y crítica política. Los objetos que se consumen en la ira popular son símbolos del poder y la acción está cargada de sentido. (...) Quemar una efigie o un icono del poder es un acto ritual, persigue poner de manifiesto que ese símbolo de la fuerza estatal es mortal, al contrario que el fuego de Zeus. Por ello, el disidente se confronta con la efigie, no insulta, sólo expresa rechazo. (...) El acto de quemar ese símbolo del poder constituido en nuestro Estado significa un rechazo a la institución de la Monarquía, forma de gobierno hereditaria. Por principio, en un sistema democrático no puede haber obstáculos a la libre circulación de opiniones, ideas o juicios de valor sobre las formas políticas. (...) En la acción incriminada - la quema simbólica de una efigie del poder - no se detecta ningún elemento que pueda objetivamente afectar a la dignidad, la fama o la propia estima del Rey o de la Reina. (...) La opinión pública libre es la sustancia de la democracia y la crítica política realiza el necesario control y el cuestionamiento de las instituciones, constituye la entraña de la democracia en su concepción clásica. Ninguna autoridad se sustrae a la crítica política. En puridad, cuanto más poder más sometimiento a la crítica, desde luego menor esfera de protección del honor de las personas que lo ocupan, siempre de manera provisional en democracia. Son indicios sobre la calidad de la esfera pública. El Rey ostenta la Jefatura del Estado, cuya forma política es la Monarquía. Además de hereditaria, por ello no electiva, no sometida a sufragio universal, la persona del Rey es inviolable e irresponsable (artículo 56.3 CE). Esos rasgos determinan que el espacio de protección de su persona, y de la propia institución, ante la crítica política sea, incluso, inferior a la de otras personas o instituciones públicas. Además, la posibilidad de reforma constitucional y de modificación de la forma política del Estado es una alternativa legítima y amparada por el ordenamiento jurídico, porque la soberanía reside en el pueblo del que emanan todos los poderes. (...) La protesta social — termina diciendo el Voto Particular firmado por el magistrado Ramón Sáez Valcárcel el día 9 de diciembre de 2008 — sólo accede a los medios 
mediante actos rituales — como, por ejemplo, la quema de los iconos del poder-, si son reprimidos penalmente se impide el desarrollo del espíritu crítico, alimento de la libertad».

\subsection{Una Monarquía con respaldo constitucional pero no democrático}

Como explicábamos al principio de este trabajo, la Monarquía española carece de legitimación democrática directa. Sin embargo, sí que goza de una cierta legitimación indirecta, lograda al aprobarse la Constitución de 1978 por las Cortes Generales y ratificarse, posteriormente, por el pueblo español en referéndum. El temor de que, al inicio de la transición política, la mayoría de ciudadanos pudiera preferir la solución republicana, determinó que las fuerzas políticas entonces hegemónicas rechazaran el valioso modelo seguido en Italia, tras la Segunda Guerra Mundial, y en Grecia, tras la caída del régimen de los Coroneles. La fórmula seguida en ambos casos consistió en someter a referéndum si el Estado debía configurarse como una Monarquía o como una República (triunfando en ambos casos la segunda opción) y, acto seguido, redactar la Constitución de acuerdo con la decisión popular mayoritaria. En España, la disyuntiva que se ofreció a los ciudadanos fue: democracia (con Rey incluido) o dictadura. Como ha subrayado el profesor Enrique Gimbernat, en nuestro país, «esa consulta no se planteó de manera independiente: a los españoles únicamente se les dio a elegir entre el sí a una Constitución democrática, a la que iba vinculada indisolublemente la Monarquía, o el no - propugnado por la extrema derecha - al establecimiento de un Estado de Derecho». Ante este panorama, añadimos nosotros, a la inmensa mayoría de españoles el voto favorable a la Constitución de 1978 no les ofreció duda, pues entendían que la posibilidad de contar, a corto plazo, con una democracia más o menos homologable con las europeas pasaba, inexorablemente, por aceptar — sin cuestionar- la Monarquía.

El profesor Gregorio Peces-Barba Martínez, después de recordar que la institución de la Corona tiene apoyo constitucional pero no democrático, afirma — con evidente sensatez — que «su perdurabilidad y su arraigo dependen de ella misma, de su talante, de su comportamiento rigurosamente ajustado a las normas constitucionales y, como dirían los republicanos clásicos, de su virtud y de su defensa sin descanso del interés general». La pervivencia de la Monarquía, sigue afirmando el primer Rector de la Universidad Carlos III de Madrid, es un plebiscito cotidiano, pues la Monarquía es escrutada por todos sus actos, tanto por los ciudadanos del común como por los actores políticos; dicha situación 
«exige un esfuerzo de prudencia, de discreción, un núcleo de buen sentido para saber distinguir, como decía Machado, las voces de los ecos».

\subsection{La superioridad ética y política de la República sobre la Monarquía}

Antes de seguir adelante, debemos dejar sentado nuestro absoluto respeto a la legalidad constitucional monárquica e incluso un cierto agradecimiento a $S$. M. Don Juan Carlos I de Borbón, que —a través de su prudencia política y su talante campechano- ha sabido, en términos generales, granjearse el respeto de los hombres públicos y la estima de las personas privadas. Pero, que un Rey cumpla su cometido con relativo acierto, no es motivo para creer en la bondad intrínseca de la institución monárquica. La Jefatura del Estado vitalicia y hereditaria, esencia de la Monarquía, supone, sin duda, una grave quiebra en el sistema democrático que, por definición, exige que todos los poderes públicos sean de duración limitada y origen electivo. Acceder a la máxima Magistratura del Estado teniendo como único mérito haber nacido en una determinada familia en un determinado orden cronológico, supone una evidente ruptura del principio democrático y de la racionalidad política. La Monarquía, por tanto, no sólo es una institución que rompe con la idea de igualdad de todos los ciudadanos ante la ley (consagrando una discriminación por razón de nacimiento, prohibida expresamente en el artículo $14 \mathrm{CE}$ ), sino que además nos priva de un derecho de especial significado democrático: el de poder ocupar algún día la Jefatura de la comunidad política a la que pertenecemos (la reciente elección de Barack Hussein Obama, negro e hijo de padre musulmán, como Presidente de los Estados Unidos, es un ejemplo muy claro de lo que queremos decir). Como ha escrito en un tono apasionado el profesor Vicenç Navarro, Catedrático de Ciencia Política en la Universitat Pompeu Fabra de Barcelona, «la cultura republicana transmite una sensación de que el poder deriva de la ciudadanía, puesto que si el Jefe del Estado no les agrada, pueden cambiarlo por otro. Es más, cualquier ciudadano puede aspirar a tal puesto de servicio público. Esta menor distancia entre el Jefe del Estado y la ciudadanía que existe en las Repúblicas versus las Monarquías se reduce todavía más cuando tal Jefe del Estado procede de las clases populares, sintiendo al Presidente como alguien suyo» (pensemos, por ejemplo, en el caso paradigmático del Presidente de Brasil Lula da Silva). Por el contrario, sigue diciendo este autor, «en las Monarquías la distancia social es intrínseca en el sistema y se traduce en España en que el Rey llama de tú a todos los ciudadanos, a los que se les exige referirse a él como de usted. Es más, existe un ambiente protocolario, cortesano y jerárquico que enfatiza 
esta distancia, como queda reflejado, por ejemplo, en que la puerta principal del Parlamento español sólo se abre cuando pasa por ella el Rey y no los representantes del pueblo».

Las Monarquías son, a nuestro juicio, instituciones en franco retroceso, anacronismos, residuos de otras épocas, anomalías democráticas, arcaísmos políticos. El propio Sabino Fernández Campo, ex Secretario General y ex Jefe de la Casa del Rey, afirma que "la Monarquía es un régimen anticuado" y "es peligroso tratar de modernizarlo en exceso». Por ello, si hasta hace doscientos cincuenta años la práctica totalidad de los Estados tenían como Jefe del Estado un Rey (con éste u otro nombre), hoy apenas unos pocos conservan esta figura. Se dice, de forma jocosa, que «con el tiempo sólo quedarán cinco Reyes: los cuatro de la baraja y la Reina de Inglaterra»; y esta última, tras los reiterados escándalos sentimentales de su familia en los últimos años, tampoco es muy seguro que consiga conservar su Corona. En nuestro días, las pocas Monarquías que quedan van desapareciendo (la última en caer ha sido la del Nepal, el 28 de mayo de 2008). Con criterio análogo, el profesor Antonio Torres del Moral, en una excelente monografía publicada en 1997, escribió: «Parecen no soplar vientos favorables para las Monarquías europeas en este fin de siglo y de milenio». Y, con tono admonitorio, añadía: «La Monarquía depende muy mucho de que los reyes y príncipes — sus profesionales - se la crean. Si ellos la cuestionan con sus hechos - ya que no con sus palabras-, nadie va a apuntalarla». Como afirmó, en la década de los ochenta, el profesor Lluís Aguiló Lúcia, «la reciente restauración monárquica en el marco político español no deja de ser una excepción e incluso una curiosidad política, fruto de las peculiares circunstancias que han acompañado al reciente proceso de transición política en el Estado español».

Por otra parte, pero sin abandonar todavía este ámbito de reflexión, queremos poner de relieve una curiosa circunstancia de nuestra historia política reciente. Desde el buen Rey Carlos III (1716-1788) hasta nuestros días, no han fallecido dos Borbones sucesivos ciñendo la Corona de España. En efecto, si uno ha muerto reinando, el siguiente lo ha hecho destronado y en el exilio. Más en concreto, Carlos III acabó sus días siendo Rey; Carlos IV, lo hizo en el exilio de Nápoles; Fernando VII, reinando; Isabel II, en el exilio de París; Alfonso XII, reinando; y Alfonso XIII, en el exilio de Roma. Pues bien, tenemos la firme convicción de que Don Juan Carlos I no romperá esta cadena histórica y morirá siendo Rey de España.

Cuando —en el ámbito académico o en el ámbito político- se plantea el clásico debate sobre las ventajas e inconvenientes de las dos formas de Jefatura de Estado, las líneas argumentales utilizadas suelen estar muy bien definidas: 
- Los partidarios de mantener la Monarquía en la España del siglo XXI suelen utilizar argumentos de carácter pragmático, apelando a la utilidad de la institución. En concreto, que Don Juan Carlos ha jugado un papel positivo en la instauración y defensa de la democracia española; que el Rey, al no deber su cargo a ningún partido político, puede actuar con mayor neutralidad; que la Monarquía es más barata que la República, porque no hay que realizar elecciones cada varios años para escoger al Jefe del Estado; que el Príncipe heredero, ya desde su infancia, se puede preparar para el alto cometido que tiene reservado; que la Familia Real española es un ejemplo de las mejores virtudes ciudadanas, y otros argumentos del mismo tenor. Justino Sinova, dentro de esta línea de pensamiento, afirma que España es un país monárquico, pero acto seguido añade que, más que monárquico, es juancarlista. Con ello quiere subrayar que - a su juicio- la disyuntiva Monarquía-República carece de sentido en nuestros días, ya que ambas formas son «excelentes» en cuanto amparan sistemas democráticos, y que las dos son reprobables en cuanto dan cobijo a formas políticas autoritarias. En base a este planteamiento, defiende la Monarquía actual argumentando que ha servido para que en España naciera y se desarrollara un sistema democrático.

- Los partidarios de propiciar el advenimiento de la III República española, por el contrario, acuden a los principios democráticos y utilizan básicamente argumentos políticos. Entre otros, que la Monarquía rompe el principio de igualdad por razón de nacimiento; que nos priva del derecho - lleno de importantísimo simbolismo- de que, algún día, nosotros mismos podamos llegar a ocupar la más Alta Magistratura del Estado; que supone una quiebra del principio democrático, que exige que todos los cargos públicos sean electivos y temporales; y que es un anacronismo propio del Antiguo Régimen, que atribuía derechos políticos por razones genéticas o históricas. Sin embargo, además de los referidos argumentos de naturaleza filosófico-política, también se esgrimen otros de carácter más práctico. En concreto, que el error de los ciudadanos en la elección de un Presidente de la República es fácilmente subsanable en las elecciones siguientes; en cambio, el error de la naturaleza al proporcionarnos un Monarca sin las suficientes cualidades intelectuales o morales no tiene otra solución que la que deriva de esperar que se complete el natural ciclo biológico. En esta línea de pensamiento, Gabriel Albiac, Catedrático de Filosofía, ha afirmado que «transmitir por herencia cromosómica la Jefatura del Estado a sus descendientes» es una locura del mismo calibre que la que sería si él pretendiera dejar su cátedra en herencia a una de sus hijas. De forma implícita, viene a reconocer que en democracia no es admisible más poder que aquel que nace del sufragio popular y se renueva periódicamente, y que la transmisión hereditaria de la Jefatura del Es- 
tado es una aberración y un disparate lógico. A juicio de Albiac, el problema básico no es que haya habido Borbones literalmente imbéciles (como Carlos IV o Isabel II) o que otros hayan sido moralmente siniestros (como Fernando VII o Alfonso XIII), el mal está en la propia institución monárquica, que es -utilizando una conocida expresión - intrínsecamente perversa. En su opinión, «el mejor tipo, al aceptar una tal trasgresión de la racionalidad política básica, esto es, al aceptar que la Jefatura del Estado le corresponda por código genético, pone la misma irracionalidad que el más malvado». De hecho, Saint-Just ya había formulado, en términos inequívocos, el mismo planteamiento, al afirmar que no se puede reinar inocentemente; a su juicio, un Rey es culpable, no por lo que haya hecho, sino por aceptar ser Rey: la Monarquía es la abominación.

A pesar de lo anterior, todavía hoy, una parte importante de los españoles se siente monárquica -0 , más exactamente, juancarlista - , pero en tanto que los republicanos no suelen cambiar de criterio - pues su opción está fundamentada en argumentos de razón y en los principios políticos democráticos, la mayoría de los monárquicos españoles lo son (igual que Thomas Hobbes en el Leviathan) por motivos prácticos, es decir, porque consideran que esta institución sigue siendo útil. Por tanto, bastaría con que - por algún motivo- dejara de ser útil o con que cometiera algún error no silenciado por los medios de comunicación (como, por ejemplo, las declaraciones mojigatas y ultra conservadoras de Doña Sofía en el libro de Pilar Urbano La Reina muy de cerca 2008_; las presiones «agobiantes» efectuadas por la "Casa Real» sobre Telecinco (que acaba de denunciar - 2009- su Consejero Delegado); o los polémicos y constantes viajes de Don Juan Carlos a Rusia, en uno de los cuales, para mayor escándalo, abatió al oso amaestrado Mitrofán, que previamente había sido emborrachado con vodka para facilitar su caza — diario ruso Kommersant, 2006) para que se produjera un amplio renacer de los sentimientos republicanos. No dejan de ser ilustrativos, en este sentido, los resultados de una encuesta realizada por Sigma Dos, dirigida por Carlos Malo de Molina, entre el 15 y el 21 de julio de 2008, y publicada en un diario nacional (El Mundo, 15 de agosto de 2008). De acuerdo con la misma, aunque los españoles otorgan a Don Juan Carlos una valoración de 7,48 puntos (muy por encima de la que se concede a los líderes de los partidos políticos), esta buena nota no se traslada a la institución que encarna, pues un 57,9 por ciento se muestra «indiferente» a la hora de decidirse por la Monarquía o la República, y sólo un 15,7 por ciento se declara monárquico. En fin, al margen del afecto personal al actual Jefe del Estado de buena parte de los ciudadanos, no puede afirmarse, ciertamente, que «los españoles beban los vientos por la Monarquía». 


\subsection{España, República parlamentaria}

Teniendo presente todo lo anterior, nuestra primera propuesta de reforma constitucional — de carácter total en lo que se refiere a la Jefatura de Estadoconsistiría, en síntesis, en sustituir la actual «Monarquía parlamentaria» por una «República parlamentaria» (podría resultar ilustrativo, a efectos de la redacción del nuevo artículo 1.3 CE, el tenor del artículo 1.1 de la Constitución helena, cuando afirma que «el régimen político de Grecia es el de una República parlamentaria»). De alguna manera, vendríamos a recoger el espíritu y el contenido esencial de la enmienda presentada por el PSOE en las Cortes Constituyentes, y que en aquellos momentos fue derrotada por la mayoría conservadora. De hecho, los razonamientos expuestos, en los debates constituyentes, por el diputado socialista Gómez Llorente para mantener su voto particular a favor de la República, señalando los defectos que a su entender presentaba la institución monárquica y las ventajas de la forma republicana, son los clásicos en esta materia.

Esta propuesta de reforma constitucional afectaría al artículo 1.3 ( «La forma política del Estado español es la Monarquía parlamentaria»), a todo el título II («De la Corona», artículos 56 a 65), y a los otros artículos sueltos que se refieren al Rey (90.2, 91, 92.2, 99.1, 99.3, 99.5, 100, 114.1, 114.2, 115.1, 117.1, $122.3,123.2,124.4,151.4,152.1,159.1$ y 160). Por tanto, aunque la parte nuclear de la reforma (el artículo 1.3 y todo el título II) están protegidos por el procedimiento agravado del artículo $168 \mathrm{CE}$, ya estudiado, los demás preceptos referidos a la Corona - individualmente considerados - podrían modificarse por el procedimiento de reforma ordinario establecido en el artículo $167 \mathrm{CE}$. El Consejo de Estado, en un supuesto muy parecido, se ha planteado esta cuestión, dictaminando que cuando la reforma constitucional que quiere llevarse a cabo «afecta a preceptos que, aisladamente considerados, podrían ser reformados por el procedimiento más simple, junto a otros que sólo pueden ser derogados o modificados siguiendo el procedimiento complejo, es este último el que se ha de seguir, pues de otro modo la reforma sería inválida en lo que a ellos respecta. Esa aplicación del procedimiento agravado a preceptos que en sí mismos podrían ser reformados por otra vía no cambia, por lo demás, la naturaleza de estos, ni impide en modo alguno que las sucesivas reformas de que en el futuro pudieran ser objeto hubieran de llevarse a cabo por un procedimiento que no sea el que la Constitución exige para cualquier cambio que les afecte sólo a ellos».

El objetivo de esta reforma radical sería, como hemos dicho, instaurar en España una "República parlamentaria», siguiendo básicamente el modelo alemán, italiano y griego; por tanto, nos situaríamos muy lejos del modelo presidencialista (de los Estados Unidos y de los países latinoamericanos) y del semi-presi- 
dencialista francés. De forma telegráfica, y sólo a modo de ejemplo orientador, expondremos alguno de los elementos básicos del que - a nuestro juiciopodría ser el estatuto jurídico del Presidente de la República española:

a) El Presidente de la República, que sería el Jefe del Estado, debería ser elegido por las Cortes Generales reunidas en sesión conjunta, pudiendo ocupar dicho cargo cualquier español de nacimiento, en el pleno goce de sus derechos civiles y políticos, mayor de cuarenta y cinco años.

b) Para resultar elegido Presidente de la República sería preciso obtener el voto favorable de dos tercios de las Cortes. La votación tendría lugar mediante escrutinio público, por llamamiento nominal, en una sesión específicamente convocada a tal efecto por el Presidente del Congreso de los Diputados. Si, después de tres votaciones consecutivas celebradas en días alternos, ningún candidato obtuviera esta mayoría, se dejarían transcurrir quince días. Tras ellos, se celebrarían nuevas votaciones en las que, para resultar elegido, bastaría la mayoría de los tres quintos de las Cortes. Si transcurrido el plazo de dos meses, a partir de la primera votación presidencial, ningún candidato hubiera obtenido el apoyo necesario, se disolverían ambas Cámaras y se convocarían elecciones generales. La nuevas Cortes deberían iniciar, inmediatamente, la elección del Presidente de la República, de acuerdo con el procedimiento anterior. En tanto no se produjera la elección presidencial, se prolongarían los poderes del Presidente de la República en ejercicio, incluso después de la expiración de su mandato y hasta la elección del nuevo Presidente.

c) El cargo de Presidente de la República tendría una duración de cinco años, permitiéndose una sola reelección. En caso de guerra, el mandato presidencial se prorrogaría hasta el final de la misma. Si dimitiera antes de la expiración de su mandato, no podría presentarse como candidato a la elección presidencial consecutiva a su dimisión. En el momento de tomar posesión de su cargo, prestaría, ante las Cortes reunidas en sesión solemne, el preceptivo juramento o promesa.

d) La condición de Presidente de la República sería incompatible con todo mandato representativo; con los cargos políticos o administrativos; con el desempeño de funciones directivas en un partido político, en un sindicato o en una iglesia, y con un empleo al servicio de los mismos; con el ejercicio de las carreras judicial y fiscal; y con cualquier actividad profesional o mercantil.

e) Una ley orgánica determinaría la asignación económica del Presidente de la República, que debería ser la más alta de las que se percibieran con fon- 
dos públicos. Al margen de su retribución, el Jefe del Estado no podría recibir —en ningún concepto- otras retribuciones, obsequios o compensaciones.

f) En cuanto a los cometidos del Presidente de la República, se le podrían atribuir — una vez analizados uno por uno- buena parte de los que actualmente se le encomiendan al Rey, aunque alguno de ellos ahora deberían residenciarse en la Presidencia del Gobierno o en la Presidencia de las Cortes. En todo caso, siempre sería preciso que sus actos fueran refrendados por el Presidente del Gobierno, los Ministros o el Presidente del Congreso de los Diputados, quienes asumirían la responsabilidad.

g) En caso de ausencia, enfermedad, muerte o cese anticipado del mandato del Presidente de la República, sus funciones serían desempeñadas provisionalmente por el Presidente del Senado. Ante la imposibilidad de este último, las funciones de aquél serían asumidas por el primero de los Vicepresidentes de esta Cámara, y, en su defecto, por los sucesivos en su orden.

h) El Congreso de los Diputados y el Senado podrían acusar al Presidente de la República ante el Tribunal Constitucional en caso de violación intencionada de la Constitución o de cualquier ley. La solicitud de formulación de la acusación debería ser presentada por, al menos, una cuarta parte de los miembros de cualquiera de las dos Cámaras. La resolución por la que se decidiera formular la acusación debería ser aprobada por una mayoría de tres quintos del Congreso de los Diputados o del Senado. La acusación correría a cargo de un comisionado de la Cámara que ha tomado la iniciativa. En caso de que el Tribunal Constitucional, por mayoría absoluta de sus miembros, lo considerase culpable de la acusación formulada, declararía su cese inmediato, iniciándose el proceso de elección de un nuevo Presidente de la República. En el supuesto contrario, esto es, que el Tribunal Constitucional rechazase la acusación, quedaría automáticamente disuelta la Cámara actuante. Una vez formulada la acusación del Presidente de la República, se podría acordar, con carácter cautelar, la suspensión en el desempeño de sus funciones.

\section{DIEZ PROPUESTAS DE REFORMA PARCIAL}

Tanto por escrito como oralmente, en sede académica y en la tribuna pública, hemos defendido la superioridad ética y política de la República sobre la Monarquía. En coherencia con ello, nuestra primera opción sería la descrita en 
el apartado anterior. Sin embargo, si aceptamos como hipótesis de trabajo que - por la peculiar transición española de la dictadura a la democracia - actualmente aún es necesaria la figura del Rey, es imprescindible afirmar que dicha institución debe adecuarse, en lo posible, a los principios democráticos que conforman el régimen político surgido de la Constitución Española de 1978. Lo que, a nuestro juicio, no ocurre en la actualidad. Además, la experiencia de más de treinta años de régimen constitucional ha puesto en evidencia que existen en nuestra Monarquía parlamentaria algunas deficiencias y ambigüedades, que provocan o podrían provocar en el futuro serias disfunciones y graves problemas. Por ello, de llevarse a cabo una reforma de la Carta Magna, podría ser un buen momento para intentar solventarlas. En efecto, si temporalmente se abandona la opción de un cambio radical en la forma de Jefatura de Estado, deberían llevarse a cabo, al menos, las reformas parciales que se indicarán en los apartados siguientes. Lo que se pretende con ellas es, en esencia, "tratar al Rey y a sus familiares como simples mortales» (Gimbernat), abandonando papanatismos y sacralizaciones ancestrales que los sitúan por encima del común de los humanos, como una especie de "héroes» de la mitología clásica, a medio camino entre los dioses y los hombres.

\subsection{La "Monarquía parlamentaria" debe definirse como una "forma de gobierno", no como una "forma de Estado"}

El artículo 1.3 CE afirma que «la forma política del Estado español es la Monarquía parlamentaria». Esta fórmula ha sido criticada por la mayoría de la doctrina, en tanto en cuanto parece confundir «forma de gobierno» con "forma de Estado». En efecto, como destaca el profesor López Guerra, en la teoría constitucional, cuando se habla de «forma de Estado» se suele hacer referencia «a la estructura y principios esenciales del Estado que definen (o contribuyen decisivamente a definir) su naturaleza». De este modo, se pueden utilizar las expresiones «Estado patrimonial», «Estado policía» o "Estado de Derecho» como formas de Estado (Biscaretti di Ruffía); o bien de «Estado constitucional» frente a «Estado autocrático» (Loewenstein); o de «Estado absoluto» frente a «Estado constitucional» (Schmitt). Asimismo, atendiendo a la distribución territorial del poder, puede hablarse del «Estado unitario», del «Estado regional o autonómico» y del «Estado federal», etc. Estas denominaciones, concluye López Guerra, ayudan «a obtener una idea general de un Estado determinado, al menos en cuanto a sus principios básicos de organización y funcionamiento». Por el contrario, la expresión «forma de gobierno» se refiere, como indica el profesor Pao- 
lo Biscaretti di Ruffía, a la «recíproca posición en que se encuentran los diversos órganos constitucionales del Estado». Criterio muy parecido al que sostiene el profesor Nicolás Pérez Serrano en su clásico Tratado de Derecho Político.

A tenor de lo anterior, superando la literalidad del precepto, debe entenderse que la fórmula del artículo 1.3 se refiere «a la articulación de los poderes constituidos, esto es, a la forma de gobierno, y no a la forma de Estado» (Miguel Satrústegui). Además, como señala este mismo autor, hay que tener presente que la expresión «Monarquía parlamentaria» del artículo 1.3 CE «sólo puede considerarse como una caracterización esencial de la forma de gobierno, y no como una descripción completa de la misma». Efectivamente, en sentido estricto, la Monarquía parlamentaria «sólo implica la separación del Rey de la función gubernamental y la responsabilidad del Gobierno ante el Parlamento». Pero otros elementos organizativos o procedimentales de esta forma de gobierno no vienen prefijados por esa definición; existiendo, en la práctica, «una variedad de soluciones en el panorama comparado de las Monarquías parlamentarias europeas» (Miguel Satrústegui).

A pesar de que creemos que, con la reforma propuesta, nuestra Constitución mejoraría su técnica jurídica, somos conscientes del limitado alcance práctico de la misma, pues — como subraya reiteradamente Antonio Torres del Moral— «la cuestión es más académica que otra cosa».

\subsection{Debe suprimirse la preferencia del varón sobre la mujer en el orden sucesorio}

El artículo 57.1 de la Constitución, al regular la sucesión en la Corona de España, afirma que, en el mismo grado, será preferido «el varón a la mujer», lo cual excepciona —o vulnera, según la óptica que se adopte- los artículos 1.1 y 14 del mismo Texto Fundamental. Como sabemos, el primero de dichos preceptos propugna «la igualdad» como valor superior del ordenamiento jurídico; y el artículo 14 consagra el principio de «igualdad ante la ley, sin que pueda prevalecer discriminación alguna por razón de... sexo». En cambio, aquel precepto, que introduce una regla tradicional en la sucesión de la Monarquía española, limita la posibilidad de que las mujeres accedan a la Corona al supuesto de ausencia de hermanos varones. Precisamente por ello, cuando el Estado español ratificó, el 16 de diciembre de 1983, la Convención sobre la Eliminación de todas las formas de Discriminación sobre la Mujer, suscrita en Nueva York el 18 de diciembre de 1979, tuvo que hacerlo bajo la reserva de que dicha ratificación «no afectará a las disposiciones constitucionales en materia de sucesión a la Corona española». 
Ante esta clara discriminación por razón de sexo, algunos autores afirman con rotundidad que el artículo 57.1 de la Constitución vulnera los indicados artículos 1.1 y 14 de la propia Constitución. Se trataría, a su juicio, de un precepto "constitucional inconstitucional», según la terminología de la doctrina y la jurisprudencia alemanas. Esta contradicción entre artículos de la misma Constitución debería resolverse dando preferencia a los preceptos más importantes sobre los menos importantes. En este sentido, no cabe duda de que los artículos 1.1 y 14 — auténticos pilares en cualquier sistema democrático- son más importantes que el artículo 57.1 — que establece una mera regla sucesoria, que ni es esencial en nuestro sistema, ni mayoritaria en las Monarquías extranjeras-. Con lo cual, concluye este sector de la doctrina, es evidente que este último precepto debe ceder ante aquéllos.

No ha sido ésta, sin embargo, la doctrina del Tribunal Constitucional ni del Consejo de Estado, que han entendido que lo que consagró el constituyente en el artículo 57.1 fue una excepción a la regla general de la igualdad y la no discriminación por razón de sexo. Así, el Tribunal Constitucional —en su Sentencia 126/1997, de 3 de julio - afirma que «la conformidad con la Constitución del orden regular de sucesión en la Corona (art. 57.1) no puede suscitar duda alguna, por haberlo establecido así el constituyente». De forma todavía más radical, el Consejo de Estado (en su Informe sobre modificaciones de la Constitución Española, de 16 de febrero de 2006) señala que, la conveniencia de eliminar la preferencia del varón sobre la mujer que establece el artículo 57.1 CE, «no nace de ninguna clase de contradicción jurídica que sea preciso salvar entre ella y la regla de no discriminación por razón de sexo que enuncia el artículo 14, ya que ambas reglas han sido establecidas por el mismo poder constituyente, una con carácter general y otra con carácter singular, limitada ésta a un único objetivo: acomodar la sucesión en el trono al orden histórico». Y añade el supremo órgano consultivo del Gobierno: «Los dos preceptos, el artículo 14 y el artículo 57.1, tienen ámbitos de aplicación distintos en el Texto Constitucional y no se interfieren mutuamente. La conveniencia de reformar el segundo no se deriva, en suma, de ninguna contradicción jurídica con el primero, sino del progresivo deterioro que ha sufrido en la conciencia social todo tipo de postergación femenina». En síntesis, pues, a juicio del Consejo de Estado, de lo que se trata con la reforma es de acomodar la Constitución «a la realidad social del tiempo presente».

Aunque la preferencia del varón sobre la mujer en la sucesión a la Corona de España ha sido tradicional en nuestro constitucionalismo histórico, hoy resulta una inadmisible discriminación por razón de sexo, un residuo de épocas pasadas, en donde las mujeres tenían restringidos sus derechos civiles y políticos, al ser 
consideradas toda su vida como menores de edad. Para demostrar lo irracional de esta regla sucesoria, basta recordar la pobreza de los argumentos que se esgrimieron en las Cortes Constituyentes en su defensa: «A las dinastías — dijo un senador- cuando les falta un varón que encarne la Corona, el hecho les produce la natural desilusión»; otro afirmó que los hombres están más capacitados que las mujeres para desempeñar los cometidos que la Corona comporta; otro, en fin, defendió la preferencia del varón para evitar un cambio de apellidos en la dinastía. Creemos que sobran los comentarios.

Para conocer los motivos profundos de una decisión política de tanto calado, apenas discutida en el Parlamento, se hace preciso hacer un poco de historia. Las Cortes Constituyentes surgidas de las elecciones de 1977, al redactar los artículos referentes a la Corona, se encontraron con un hecho consumado del que, en aquellos momentos de inicio de la transición política, no pudieron escapar: Don Felipe de Borbón había sido proclamado Príncipe de Asturias - es decir, heredero a la Corona - en Covadonga el día 1 de noviembre de 1977. Cuando nos preguntamos acerca de ¡cuál era el fundamento democrático de un acto tan trascendente como era el de preterir a las mujeres en la sucesión al trono de España?, debemos responder que ninguno. La Casa de Borbón, por los motivos que estimó oportunos y que nunca ha explicado, prefirió colocar como cabeza de serie a su descendiente varón antes que seguir el orden cronológico del nacimiento. La doctrina constitucionalista ha sido muy dura al enjuiciar el acto de Covadonga. Los autores más moderados han afirmado que se trató de un acto de naturaleza jurídica difusa e imprecisa; otros más decididos han subrayado que fue un acto, política y jurídicamente, poco delicado con las Cortes Constituyentes, que ya estaban iniciando sus trabajos; finalmente, un tercer grupo, entre los que nosotros nos situamos, estima que se trató de una clara coacción a la libertad del Parlamento que, con un Príncipe de Asturias proclamado y la atenta mirada del Ejército y los sectores franquistas aún en el poder, se vio incapaz de contradecir la expresa voluntad de S. M. el Rey. La ausencia de los representantes del PSOE y del PCE al acto de Covadonga no estaba, pues, falta de fundamento, máxime si tenemos en cuenta que la Diputación Provincial asturiana, que tenía en buena medida el protagonismo del acto, carecía de cualquier legitimidad democrática.

Durante los debates parlamentarios, el senador Villar Arregui puso el dedo en una llaga que no quiso ser vista. En efecto, a su juicio, «mantener el precepto (se refería al actual artículo 57.1) en los términos en que está concebido supone... una vejación a todas las mujeres de España, que no entenderán que los hombres que están elaborando esta Constitución les dediquen bellas palabras no discriminatorias a la hora de proclamar valores, pero que las discriminen radi- 
calmente a la hora de organizar instituciones». El profesor Antonio Torres del Moral, haciéndose eco de dos enmiendas que se presentaron en la Cámara Alta (una del grupo parlamentario Entesa dels Catalans y otra del propio senador Villar Arregui), ha señalado que, si la sucesión de Don Felipe de Borbón y Grecia se hacía políticamente intocable, las Cortes Constituyentes hubieran podido arbitrar la siguiente solución de compromiso: declarar heredero del actual Rey a Don Felipe y establecer, para el futuro, un orden sucesorio sin discriminaciones por razón de sexo. Sin embargo, esta propuesta, tan puesta en razón, fue rechazada por el Constituyente español, que mostró —en este punto- una «miopía de no pocas dioptrías", pues "tuvo la posibilidad, y la perdió, de ser pionero en el establecimiento del principio de igualdad en la sucesión en la Corona» (Torres del Moral). Además, como prueba de la referida estrechez de miras, basta recordar que aquella propuesta surgida - y rechazada - en las Cortes Constituyentes es, precisamente, la solución que ha sugerido el Consejo de Estado en su citado Informe de 16 de febrero de 2006.

Hoy han transcurrido más de treinta años desde la entrada en vigor de la Constitución Española de 1978, la conciencia colectiva sobre cuál debe ser el papel de la mujer en la sociedad ha cambiando sobremanera, considerándose absolutamente inaceptables todas las discriminaciones por razón de sexo. Por ello, suprimir la preferencia del varón consagrada en el artículo 57. 1 CE sería, sin duda, ampliamente aceptada por el pueblo español, y nos pondría en el mismo camino que han seguido otras Monarquías democráticas europeas en los últimos años, consagrando la plena igualdad por razón de sexo en el acceso a la Corona. Así ha ocurrido, en efecto, en Suecia (1980), Holanda (1983), Noruega (1990), Bélgica (1991) y, muy recientemente, Dinamarca (2009). Además, en el Reino Unido, aunque todavía se mantiene la preferencia del varón sobre la mujer, existen iniciativas políticas favorables a la reforma con un amplio apoyo social, que sólo por motivos de conveniencia coyuntural se está postergando.

En España, en el momento de redactar estas líneas, está abierto, en los medios de comunicación y en la propia clase política, un debate sobre la conveniencia o necesidad de reformar la Constitución en el punto que posterga a las mujeres frente a los varones en la sucesión a la Corona (ya que, precisamente, el primer descendiente de los Príncipes de Asturias ha sido una niña). De hecho, el Consejo de Ministros de día 4 de marzo de 2005 adoptó el Acuerdo de solicitar al Consejo de Estado que se pronunciase acerca del modo de eliminar la preferencia del varón sobre la mujer en el acceso al trono, consagrada en el artículo 57.1 CE, «salvaguardando expresamente los derechos del actual Príncipe de Asturias en relación con la sucesión en la Corona de España». Dicha consulta fue contestada con el importante y ya citado Informe sobre modificaciones de la 
Constitución Española, aprobado el 16 de febrero de 2006, en el que se afirma que «la igualdad ante la ley de mujeres y hombres es un principio universalmente reconocido y básico del ordenamiento jurídico español, tanto en los ámbitos públicos como en los privados, tras épocas de preterición femenina, ya superadas. Ello ofrece base suficiente para eliminar del artículo 57.1 de la Constitución la preferencia del varón que aún figura en él, sin que sea preciso invocar otros argumentos». A partir de esta consideración, y adoptando las medidas necesarias para que el actual Príncipe de Asturias no decaiga en su condición de heredero, el Consejo de Estado propone como nuevo texto del artículo 57.1 CE el siguiente: «La Corona de España es hereditaria en los sucesores de S. M. Don Juan Carlos I de Borbón, legítimo heredero de la dinastía histórica. La sucesión en el trono corresponde a su hijo, el Príncipe heredero Don Felipe de Borbón, y después seguirá el orden regular de primogenitura y representación, siendo preferida siempre la línea anterior a las posteriores; en la misma línea, el grado más próximo al más remoto; y en el mismo grado, la persona de más edad a la de menos». Como vemos, además de salvaguardar expresamente los derechos del actual Príncipe de Asturias, con preterición de su hermana mayor - Doña Elena de Borbón y Grecia—, se suprime la frase: «el varón a la mujer, y en el mismo sexo".

Esta fórmula del Consejo de Estado ha sido, a nuestro juicio, mejorada con dos propuestas del profesor Antonio Torres del Moral. De acuerdo con la primera, la excepción a la igualdad de sexo para la sucesión de Don Felipe de Borbón debería redactarse «en términos no estrictamente personales, sino de línea sucesoria, lo que es más preciso y evita mejor los problemas que pudieran eventualmente plantearse». A tenor de la segunda propuesta, la palabra «sucesores» del artículo 57.1 debería sustituirse por «descendientes», que era el término que utilizaban — de forma más acertada - nuestras Constituciones históricas. En efecto, a juicio del catedrático de la UNED, «con los descendientes hay suficiente para cubrir todas las eventualidades que se puedan avizorar en un futuro de setenta años y lo previsible es que siga siéndolo en lo sucesivo con mayor motivo»; «tiene la ventaja de conectar mejor con la opinión pública, que rechaza ostensiblemente la posibilidad (bien es verdad que muy remota) de una sucesión en cabeza de determinadas personas»; $\mathrm{y}$ «se corresponde además con la conveniencia de poner un límite a las líneas llamadas en Derecho a la sucesión» (que es, precisamente, el presupuesto que inspira el tercer apartado del referido artículo 57). A tenor de las dos propuestas anteriores, amén de la sugerida por el Consejo de Estado, la redacción que proponemos del artículo 57.1 es la siguiente: «La Corona de España es hereditaria en los descendientes de S. M. Don Juan Carlos I de Borbón, legítimo heredero de la dinastía histórica. La primera 
linea llamada a suceder en el trono es la encabezada por S. A. Don Felipe de Borbón y Grecia. En adelante, la sucesión seguirá el orden regular de primogenitura y representación, siendo preferida siempre la línea anterior a las posteriores; en la misma línea, el grado más próximo al más remoto; y en el mismo grado, la persona de más edad a la de menos».

Las fuerzas políticas, prácticamente sin excepción, se han mostrado favorables a la supresión de esta secular discriminación. Sin embargo, por razones más políticas que jurídicas (en concreto, el temor de que el referéndum reformador del artículo 57.1 CE se convirtiera en un plebiscito sobre la propia Monarquía, con resultados imprevisibles), dicha reforma constitucional puede tardar bastantes años e incluso no llegar a producirse nunca, a menos que el posterior nacimiento de un varón la haga jurídicamente imprescindible para evitar que las expectativas de derecho de la infanta Leonor se vean, como tantas veces ha ocurrido en nuestra historia, preteridas ante su hermano menor (éste fue, por ejemplo, el caso de la hija mayor de Alfonso XII, la Princesa de Asturias Doña María de las Mercedes de Borbón y Habsburgo, que vio sus derechos postergados por el nacimiento de su hermano Alfonso, hijo póstumo del Rey). Preocupado por la posibilidad de que el referéndum que culminaría este procedimiento de reforma constitucional se convirtiera en una plataforma publicitaria a favor de la República, el profesor Pedro González-Trevijano afirma que, en todo caso, la reforma de la preferencia del varón sobre la mujer en la sucesión a la Corona "habrá de plantearse junto con el resto de las sugeridas enmiendas (denominación de las Comunidades Autónomas, Derecho comunitario y Senado). De no ser así — sigue diciendo el Rector de la Universidad Rey Juan Carlos- podríamos terminar convirtiéndola en un injustificado plebiscito sobre la aceptación mayor o menor de la Monarquía». En la misma línea de pensamiento, el profesor Enrique Belda, tampoco nada sospechoso de republicanismo, se muestra contrario a la reforma constitucional si ésta sólo ha de referirse a la supresión de la preferencia sucesoria del varón. Esta cautela de los autores más favorables a la Monarquía parlamentaria es lógica, pues — como apunta, con propósito descriptivo y no valorativo, el profesor Torres del Moral — «no puede ocultársenos que, habiendo como hay en España muchos individuos, grupos y partidos republicanos, algunos de ellos más ejercientes y reivindicativos que otros, podrían aprovechar la coyuntura para plantear no ya esta reforma y ni siquiera la posición del actual Heredero, sino, sobre todo, la propia forma política monárquica». 


\subsection{Las Cortes deben poder inhabilitar al Rey de forma permanente, al objeto de que su «inviolabilidad» no se convierta en una técnica para eludir la acción de la justicia}

El artículo 56.3 CE afirma que «la persona del Rey es inviolable». La doctrina, como hemos indicado, entiende que la inviolabilidad vendría ser un «status» personal de inmunidad frente a las leyes penales. Ello nos lleva inexorablemente a plantearnos qué sucedería en el supuesto posible (aunque no probable, ni nada deseable) de un Rey delincuente (no hace falta pensar en supuestos antiguos de Reyes asesinos o violadores, sino en supuestos más posibles, como el de un Monarca que comete un homicidio imprudente por conducir bajo los efectos del alcohol o que decide defraudar a Hacienda). Actualmente, el Rey de España, por ser constitucionalmente inviolable, no está sujeto a las leyes penales $y$, por tanto, si no abdica (decisión siempre voluntaria) no será posible imponerle la sanción correspondiente a su conducta delictiva. Este planteamiento resulta incompatible con la existencia de un Tribunal Penal Internacional, que no admite excepciones personales a su jurisdicción. Además, no parece muy coherente que los tribunales españoles se consideren competentes para juzgar penalmente a Jefes o antiguos Jefes de Estado extranjeros y, en cambio, nuestra Constitución afirme que el nuestro no responde ante la Justicia.

El profesor Enrique Gimbernat, en un brillante artículo titulado «Los privilegios penales de la Familia Real», ha escrito: «El artículo 56.3 CE establece que la persona del Rey es inviolable... Ello quiere decir que el Rey puede matar, violar o robar sin que por esos hechos sea posible abrir diligencias penales contra él, lo que vulnera no sólo el principio de igualdad ante la ley, sino también el de la tutela judicial efectiva (art. 24.1 CE), pues los perjudicados por los eventuales asesinatos, violaciones o robos reales ni pueden exigir ante los tribunales que esas conductas punibles sean compensadas con la imposición de una pena al autor, ni tan siquiera obtener un resarcimiento económico por los daños sufridos con la prestación económica que lleva consigo la responsabilidad civil derivada del delito. Esta inviolabilidad del Jefe del Estado español — sigue diciendo el eminente penalista - apenas tiene paralelo en el Derecho Comparado actual». En esta línea, el artículo 27.1 del Estatuto de la Corte Penal Internacional afirma textualmente: «El presente Estatuto será aplicable por igual a todos sin distinción alguna basada en el cargo oficial. En particular - continua señalando este precepto-, el cargo oficial de una persona, sea Jefe de Estado o de Gobierno, miembro de un Gobierno o Parlamento, representante elegido o funcionario de Gobierno, en ningún caso la eximirá de responsabilidad penal ni constituirá per se motivo para reducir la pena». Pues bien, en los más de ciento 
cincuenta países que, hasta este momento, han ratificado dicho Estatuto de la Corte Penal Internacional no hay ninguna norma «que consagre la impunidad de los Jefes de Estado, sean éstos Emperadores, Reyes o Presidentes de la República». Tras este rotundo planteamiento, el profesor Enrique Gimbernat afirma que España sólo podía ratificar este importantísimo documento internacional suprimiendo el carácter «inviolable» que se aplica al Rey en el artículo 56.3 CE. Sin embargo, y amparándose en el muy discutible dictamen del Consejo de Estado de 22 de julio de 1999 (que parecía confundir «inviolabilidad» con «irresponsabilidad»), se adoptó la decisión legislativa «disparatada de ratificar el Estatuto de la Corte Penal Internacional sin suprimir» la inviolabilidad del Monarca. Si tenemos en cuenta que la Constitución Española, según reiterada doctrina del Tribunal Constitucional, no puede ser reformada por tratados internacionales (sino sólo a través de los procedimientos previstos en el título X de la misma), debemos concluir que, lamentablemente, el Estatuto de la Corte Penal Internacional en España es inconstitucional, «por oponerse al artículo 56.3 $\mathrm{CE}$, siendo su pretendida vigencia en España nula de pleno Derecho». Tras calificar los privilegios penales de los que goza el Rey de «intolerables y antidemocráticos», el profesor Gimbernat afirma - con criterio que nosotros compartimos plenamente- que «esos privilegios deben desaparecer de raíz y para siempre; y cuanto antes, mejor». En la misma línea de pensamiento, el profesor Jesús González Pérez ha subrayado que, «en un Estado de Derecho, es inconcebible cualquier exclusión... en razón de la persona», no pudiendo existir "personas inmunes al control judicial».

A nuestro juicio, para resolver este problema, la solución más coherente tal vez, la única compatible con el Estado de Derecho que proclama la Constitución de 1978 - sería que las Cortes (por mayoría cualificada) pudieran inhabilitar permanentemente al Rey para el ejercicio de su oficio y, acto seguido, pusieran en marcha el mecanismo sucesorio del artículo $57 \mathrm{CE}$. Con lo cual, el Monarca presuntamente delincuente, al ser despojado de su cargo, ya dejaría de ser Rey y podría ser procesado (igual que un Presidente de la República al finalizar su mandato), con todas las garantías que fueran precisas y todas las cautelas que la excepcionalidad de la situación hiciera aconsejable. Con criterio análogo, ya en 1982, el profesor Luis López Guerra había escrito: «en el remoto caso de que el Monarca llevase a cabo un acto materialmente delictivo y penalmente tipificado, cabría aplicar el artículo 59.2, es decir, considerar que el Rey se halla inhabilitado para ejercer su cargo».

Pues bien, con la actual Constitución es dudoso que esta solución, que a nuestro juicio pondera de forma adecuada todos los intereses en juego, pudiera llevarse a cabo. En efecto, el artículo 59.2 CE, con una redacción que a fuerza de 
querer ser respetuosa con el Monarca resulta bastante confusa, afirma: «Si el Rey se inhabilitare para el ejercicio de su autoridad y la imposibilidad fuera reconocida por las Cortes Generales, entrará a ejercer inmediatamente la Regencia el Príncipe heredero». Este precepto sólo parece contemplar la inhabilitación temporal, pues la respuesta que le da es siempre la Regencia, que es una figura de carácter provisional, que suple de forma interina al titular de la Corona, pero no lo sustituye. En resumen, pues, la reforma de la Constitución que proponemos, además de mejorar la redacción del artículo 59.2 (al objeto de llamar a las cosas por su nombre y obviar eufemismos innecesarios en las sociedades adultas), debería prever de forma expresa que las Cortes puedan inhabilitar al Rey no sólo de forma temporal, sino también de forma permanente, tanto por motivos de salud (física o psíquica) como por cuestiones de indignidad en su vida pública o privada (que, en el caso de un Jefe del Estado, nunca puede del todo privada).

\subsection{El refrendo debe extenderse al nombramiento y relevo de los miembros civiles y militares de la Casa del Rey}

El segundo inciso del artículo 56.3 CE afirma que los actos del Rey estarán siempre refrendados, precisando — a continuación — que carecen de validez sin dicho refrendo. Ésta es la regla general. Sin embargo, este mismo precepto nos advierte que el artículo 65 consagra dos excepciones a la misma: la distribución de la cantidad global que recibe de los Presupuestos Generales del Estado («El Rey recibe de los Presupuestos del Estado una cantidad global para el sostenimiento de su Familia y Casa, y distribuye libremente la misma»: art. 65.1) y el nombramiento y relevo de los miembros civiles y militares de su Casa («El Rey nombra y releva libremente a los miembros civiles y militares de su Casa»: art. 65.2). Éstas son, pues, las dos únicas excepciones de actos regios que no precisan refrendo. Pues bien, a nuestro parecer, la primera de estas excepciones (con los límites que se indicarán en la siguiente propuesta de reforma constitucional) es admisible. No así, en cambio, la que se refiere a los nombramientos de los miembros civiles y militares de la Casa del Rey, pues nuestra experiencia constitucional nos enseña que son cargos que encierran un gran poder (efectivo y, sobre todo, de influencia) y de cuyo acierto nunca se puede estar totalmente seguro (recordemos, sin ir más lejos, el nombramiento del general Alfonso Armada Comín como Secretario General de la Casa del Rey, el cual fue posteriormente condenado por participar en el golpe de Estado del 23 de febrero de 1981). Por ello, para evitarle al Rey posibles responsabilidades políticas ante nombramientos que posteriormente resultaran poco acertados, pro- 
ponemos que los mismos sean refrendados con carácter preceptivo por el Presidente del Gobierno. Este requisito limitaría la facultad de elección del Monarca, pues ante la negativa del Jefe del Ejecutivo a refrendarle una propuesta debería necesariamente descartarla; sin embargo, le garantizaría la irresponsabilidad por las consecuencias desafortunadas de la elección equivocada. De hecho, con la actual redacción de la Constitución, aunque estos actos no requieren refrendo, tampoco lo tienen prohibido, y - desde mediados de los años ochenta - el Rey le ha solicitado el refrendo al Presidente del Gobierno, a los efectos de conseguir el indicado beneficio de la irresponsabilidad regia. A pesar de ello, entendemos que es preciso que esta práctica se consagre, con carácter obligatorio, en el Texto Constitucional. $\mathrm{O}$, dicho más claramente, que los actos de nombramiento y relevo de los miembros de la Casa del Rey no se excepcionen de la regla general de los actos regios, que exigen para su validez el correspondiente refrendo.

\subsection{Deben controlarse los gastos del Rey realizados con dinero público}

Como acabamos de exponer en el punto anterior, el artículo 65.1 CE consagra la libertad del Rey (esto es, la no necesidad de refrendo) para distribuir la cantidad global que recibe de los Presupuestos Generales del Estado (para el año 2008 dicha cantidad ascendió a la cifra de 8.660.000 euros, y para el 2009 están presupuestados 8.900 .000 euros). Y decíamos, también, que dicha excepcionalidad a la exigencia de refrendo de un acto regio nos parecía aceptable, con una serie de límites constitucionales. Ahora vamos a referirnos a ellos.

La fórmula que consagra actualmente la Constitución (el Rey «distribuye libremente» la cantidad global que recibe del Presupuesto del Estado) ha permitido que este aspecto del funcionamiento de la Monarquía española esté rodeado de un manto de secretismo absolutamente inadmisible en un Estado democrático de Derecho. Basta pensar que la negativa a dar información al respecto ha llevado incluso a vetar preguntas parlamentarias, lo que ha provocado que el diputado afectado (Joan Tardà, de ERC) haya interpuesto el correspondiente recurso de amparo ante el Tribunal Constitucional, por la vía del artículo 42 de la LOTC. Es preciso, como reconocía el diario El Mundo en su documento "Cien propuestas para la regeneración democrática de España» publicado en el año 2004, que los presupuestos de la Casa Real estén sometidos a la necesaria transparencia. En este sentido, el nombramiento, el 27 de agosto de 2007 (Real Decreto 1.106/2007), de un interventor para que lleve las cuentas de la Casa Real fue un primer movimiento en dicha línea (sin duda, debido a la 
presión mediática y política, pues numerosas voces insistían e insisten en la necesidad de conocer las cuentas del Jefe del Estado y el destino del dinero que las Cortes le asignan anualmente). Sin embargo, este pequeño avance es, a nuestro entender, totalmente insuficiente, siendo necesario que la Constitución garantice fórmulas de control y, en su caso, de responsabilidad. De hecho, la actual situación de opacidad y oscurantismo de las cuentas del Rey es una anormalidad en lo que es práctica habitual en todas las Monarquías democráticas de la Europa occidental. Así, a modo de ejemplo, en el Reino Unido existe la Royal List, en la que se indica la cantidad que se dedica a cada miembro de la Familia Real y su destino concreto. En efecto, como señala Dickie Arbiter, que durante muchos años fue secretario privado de la Reina Isabel II de Inglaterra y de los Príncipes de Gales, la Monarquía británica es totalmente transparente, pues, por ejemplo, «sabemos perfectamente cuántos viajes ha hecho el príncipe Andrés, cuántos coches ha usado este año, cuántos kilómetros ha hecho en ellos. Y yo creo - concluye- que por eso la Monarquía es tan popular en ese país, porque no se esconde nada a la gente». Todo lo contrario de lo que sucede, lamentablemente, con los dineros públicos que cada año se entregan al Rey de España. Como subrayaba el editorial del citado periódico de día 29 de agosto de 2007, «de lo que se trata, en última instancia, es de controlar el destino del dinero público, y es lógico que haya transparencia. La opacidad sólo contribuye a crear una aureola de secretismo, a levantar sospechas" y a dar argumentos "a quienes aspiran a una República como modelo de Estado».

Nuestra propuesta, en este ámbito, pasaría porque todos los gastos del Rey con dinero público estén sometidos al control de la Intervención General del Estado y del Tribunal de Cuentas, pues — como apuntó Gaspar Llamazares- el interventor (jubilado) nombrado por el Monarca se acerca más a un «gerente de las cuentas privadas del Rey», que a un órgano de efectivo control. Ciertamente, se trata de un mero empleado de la Casa del Rey, por lo que carece de la imprescindible independencia para realizar una fiscalización que tenga un mínimo de credibilidad. La misma preocupación está presente en la propuesta número quince del documento "Cien propuestas para defender y fortalecer la democracia» (publicado en el diario El Mundo, 7 de febrero de 2008), redactada con el siguiente tenor: «La Casa Real deberá presentar ante el Congreso de los Diputados la contabilidad anual de sus gastos, incluyendo la relación de personas que reciben asignaciones públicas». No se olvide que, como afirmó en sede parlamentaria el diputado de ERC Joan Puig al discutirse los Presupuestos Generales del Estado para el año 2008, el Rey "cobra en un día más que un mileurista en un año o cien veces más que el Presidente del Gobierno». 


\subsection{Deben fijarse las incompatibilidades de los miembros de la Familia Real en el ámbito económico-privado}

Los negocios y otras actividades económico-privadas del Rey y de los demás miembros de la Familia Real (que deseen mantener sus derechos sucesorios a la Corona) deben estar fuertemente limitados por un conjunto de incompatibilidades fijadas en la propia Constitución, al objeto de prevenir situaciones que puedan originar conflictos de intereses. Asimismo, deberán hacerse públicas las donaciones y regalos que reciban, sea en el concepto que sea, de particulares o empresas.

En coherencia con lo anterior, creemos que serían aplicables a los miembros de la Familia Real la filosofía general y algunos de los preceptos de la Ley 5/2006, de 10 de abril, de regulación de los conflictos de intereses de los miembros del Gobierno y de los altos cargos de la Administración General del Estado. Así, y a modo de ejemplo, proponemos que el Rey, su cónyuge y las personas con derechos sucesorios estén obligados a formular ante un Registro de Bienes y Derechos Patrimoniales de los Miembros de la Familia Real, en los términos que establezca una ley, una declaración patrimonial, comprensiva de la totalidad de sus bienes, derechos y obligaciones. Esta declaración, que debería reiterarse cada cinco años, comprendería, al menos, los siguientes extremos: los bienes, derechos y obligaciones patrimoniales que posean; los valores o activos financieros negociables; las participaciones societarias; el objeto social de las sociedades de cualquier clase en las que tenga intereses el declarante, su cónyuge (o persona con quien conviva en análoga relación de afectividad), sus hijos dependientes y personas tuteladas. Este nuevo Registro de Bienes y Derechos Patrimoniales de los Miembros de la Familia Real debería contar con un sistema que garantizase la inalterabilidad y permanencia de sus datos, así como la alta seguridad en el acceso y uso de éstos. El contenido de las declaraciones de bienes y derechos patrimoniales de los miembros de la Familia Real se publicaría en el Boletín Oficial del Estado, en los términos previstos legalmente. En todo caso, por lo que se refiere a los bienes patrimoniales, se publicaría una declaración comprensiva de la situación de los declarantes, omitiéndose aquellos datos referentes a su localización y salvaguardando, en todo caso, la privacidad y seguridad de sus titulares.

Recordemos, para ejemplificar la importancia de todo lo anterior, que cuando Don Juan Carlos de Borbón y Doña Sofía de Grecia se instalaron en Madrid en 1962, como posibles candidatos en espera a la Corona de España, disponían de unos recursos económicos propios muy modestos. Hoy, según algunos medios de información, la fortuna del Rey está entre las diez mayores de nuestro país, lo que explica que el diario belga Het Laatste Nieuws, al elaborar la lista de los reyes 
más ricos de Europa, haya situado a Don Juan Carlos I de España en un envidiable tercer lugar, con una fortuna estimada de 1.700 millones de euros (lo que contrasta bastante con los 12,4 millones de euros de Alberto II de Bélgica). Sin tener la menor duda de que este incremento patrimonial de nuestros Monarcas se ha producido dentro de la más absoluta legalidad, pensamos que sería deseable - para evitar sospechas infundadas - conocer las vías que han permitido un enriquecimiento tan notable. Con ello, acusaciones tan graves como las de José Antonio Barroso, alcalde de Puerto Real (Cádiz), en el sentido de que «el Rey está implicado de forma corrupta en negocios que no son habituales en la clase política», no alcanzarían — por increíbles- el menor eco en los medios de comunicación.

En la misma línea de pensamiento, debemos afirmar que las reiteradas noticias (aparecidas en importantes periódicos de Madrid, a finales del año 2008) de que el Rey (haciendo una intensa labor de lobby a favor de sus - muy visitados- amigos rusos) presionó al Gobierno de España para que permitiera al grupo energético ruso Lukoil (muy próximo al Kremlin y dependiente del mismo) hacerse con un treinta por ciento del accionariado de la empresa petrolera española Repsol YPF, son extremadamente graves. Por ello, debe darse a la opinión pública toda la información que exista al respecto, para que quede claro que esta noticia no es cierta o, si por desgracia lo es, que nunca más vuelva repetirse por parte del Monarca una conducta similar.

\subsection{Debe determinarse de forma inequivoca la autoria (y consiguiente responsabilidad) de los discursos del Rey}

Una de las cuestiones pendientes en nuestro sistema constitucional es la de determinar, de una vez por todas, la autoría de los discursos del Rey: ¿̨os escribe la Zarzuela?, ¿'los redacta el Gobierno?, ¿los prepara la Zarzuela y luego los remite al Gobierno para que les dé el visto bueno?, ¿los elabora el Gobierno y posteriormente los envía a la Casa del Rey para que, en su caso, los retoque?, ¿los preparan conjuntamente la Zarzuela y el Gobierno?... La verdad es que este extremo está envuelto en una notable nebulosa, y es aquí donde radican muchos de los males que aquejan a la Monarquía española. Nos estamos refiriendo, como es obvio, a las duras críticas que, a menudo, recibe el Rey por el contenido de sus discursos que no agradan a una parte de la población (por ejemplo, cuando defendió el pleno ingreso de España en la OTAN, el incremento del gasto militar o la autocontención de los periodistas en sus críticas a los políticos). 
Para abordar correctamente esta delicada cuestión, debemos recordar que todos los actos del Rey (con las excepciones indicadas) necesitan refrendo, es decir, precisan que el Presidente del Gobierno, los Ministros o el Presidente del Congreso de los Diputados los asuman como propios y, por tanto, se hagan responsables de los mismos (art. $64 \mathrm{CE}$ ); los actos del Rey sin refrendo, como hemos dicho, carecen de cualquier validez. En coherencia con lo anterior, entendemos que el mejor sistema - y posiblemente el único conforme con la Constitución - es que todos — absolutamente todos- los discursos del Rey sean redactados por el Gobierno de turno, y así se diga pública y claramente. De este modo, el Rey se limitaría a leer el discurso que expresase la posición del Gobierno democráticamente elegido, y en lógica consecuencia las críticas a su contenido se dirigirían al Gobierno y nunca al Monarca, que sería ajeno al mismo, y que se habría limitado a aportar su voz y la solemnidad de la Jefatura del Estado. Cuando en Gran Bretaña la Reina lee un discurso durante un Gobierno laborista, proclama las ventajas y los aciertos de las políticas progresistas; y cuando hace un discurso bajo un Gobierno de derechas, expresa las excelencias del ideario conservador. De seguirse este modelo, sustrayendo al Rey cualquier opinión política propia, podría cumplir más correctamente las funciones que le asigna la Constitución de 1978. El Rey, por ser quien es, tiene grandes privilegios de todo orden, pero también, si quiere respetar el papel que le corresponde en una Monarquía parlamentaria, tiene importantes limitaciones, entre ellas la de ver su libertad de expresión fuertemente recortada. Además, a nuestro juicio, sería muy conveniente — sobre todo para la propia institución monárquicaque dichas limitaciones verbales también fueran respetadas por el cónyuge e hijos del titular de la Corona. Recordemos, en este sentido, el desgaste político que sufrió la Monarquía española, a finales de 2008, por las desafortunadas declaraciones de la Reina en el polémico libro de Pilar Urbano. Es cierto que la Constitución no otorga (salvo lo dispuesto para la Regencia) ninguna función constitucional a la esposa del Rey o al marido de la Reina, ni forman parte de la Corona - que es evidentemente un órgano constitucional unipersonal-, pero tienen una gran relevancia dentro de la institución monárquica; por ello, se les debe exigir la misma neutralidad que al Rey o a la Reina.

\subsection{Es preciso igualar el titulo y el tratamiento que se otorgan a la esposa del Rey y al marido de la Reina}

Hemos visto que el artículo 58.1 CE habla de «la Reina consorte» y del «consorte de la Reina». Por tanto, la mujer que contrae matrimonio o está casada 
con el Rey dinástico adquiere el título de «Reina» (aunque sea con el adjetivo añadido de "consorte»); por el contrario, al varón que contrae nupcias con la Reina dinástica se le niega el título de Rey, denominándolo simplemente «consorte de la Reina». En el texto que salio de la Ponencia constitucional no existía esta distinción, ya que se aludía al "consorte del Rey o de la Reina». Dicha diferencia de título del cónyuge de la persona regia, en función de que sea hombre o mujer, se debió a una enmienda in voce del Grupo Parlamentario de Unión de Centro Democrático en la Comisión de Asuntos Constitucionales del Congreso, defendida por el diputado Martín Oviedo. La argumentación que se esgrimió, y que - a pesar de ser absolutamente hueca- convenció a la Comisión, fue que «el consorte del Rey es, en realidad, la Reina consorte, mientras que, evidentemente, no ostenta el título de Rey el consorte de la Reina» (Entrena Cuesta). Como decimos, se trató de un juego de palabras sin ningún contenido argumentativo; sin embargo, a partir de esta fase del iter constituyente, el actual artículo 58 ya fue aprobado sin debate alguno hasta la versión definitiva. Por otra parte, en coherencia con esta distinción constitucional, el Real Decreto $1.368 / 1987$, de 6 de noviembre, sobre régimen de títulos, tratamientos y honores de la Familia Real y de los Regentes, establece que la Reina consorte recibirá el tratamiento de «Majestad» (artículo 1.2); por el contrario, al consorte de la Reina, al que le corresponderá la dignidad de «Príncipe», sólo recibirá el tratamiento de «Alteza Real» (artículo 1.3).

Estas diferencias de título y de tratamiento según que el cónyuge sea hombre o mujer, favorables a esta última, han provocado que algún autor haya afirmado que estamos ante una "galantería constitucional», aunque es más correcto hablar de "un caso de discriminación inversa» (López Guerra). El profesor Alzaga Villaamil afirma que es una práctica tradicional en el Derecho histórico español; sin embargo, Menéndez Rexach precisa que, al menos durante la época de Isabel II, también se llamó «Rey» a su esposo, Don Francisco de Asís de Borbón. Por su parte, la profesora Gómez Sánchez afirma que «las razones de tal diferenciación son históricas y quizá se justifiquen en razón de ello, pero resultan escasamente comprensibles en el ordenamiento jurídico actual en el que, el principio de igualdad, debe presidir el desarrollo legislativo de la Constitución».

A nuestro parecer, esta discriminación inversa es, de forma implícita, una especie de compensación por la preferencia que el artículo $57.1 \mathrm{CE}$ da al varón sobre la mujer en el orden sucesorio. Además, esta diferencia de trato constitucional puede esconder — sutilmente— una idea «machista»: la mujer que se casa con el Rey puede llamarse Reina porque nunca hará sombra al Rey dinástico, su marido; en cambio, se niega este derecho al hombre que se casa con la Reina porque, dada su mayor fuerza y presencia, puede llegar a anular políticamente a 
la verdadera Reina, motivo por el cual nunca se le permitirá que use la denominación de Rey.

En todo caso, dado que ya hemos propuesto la supresión de la preferencia sucesoria por razón de sexo masculino, por una parte, y que la hipotética intención oculta apuntada parece poco realista en los tiempos que corren, por otra, entendemos que es imprescindible igualar el título que se da al marido de la Reina y a la esposa del Rey; siendo indiferente, a nuestro juicio, que se utilice cualquiera de los dos que consagra actualmente la Constitución. En coherencia con ello, entendemos que también resulta necesario unificar el tratamiento que les corresponderá; que deberá ser el de "Majestad» si se les concede el título de Rey o Reina consorte, y de "Alteza Real» si se opta por denominarlos — más modestamente- consorte del Rey o de la Reina.

\subsection{Es necesario fijar los principios básicos del estatuto jurídico del Príncipe de Asturias}

El título de Príncipe de Asturias fue otorgado, por vez primera, en 1388. El distinguido con tal dignidad fue el infante Enrique, hijo mayor de Juan I de Castilla y Leonor de Aragón, heredero y futuro Rey de Castilla dos años más tarde. Con dicho título se designó, a partir de entonces, a todos los herederos y herederas de la Corona de Castilla (como los «Delfines» franceses y los «Príncipes de Gales» ingleses). Después del matrimonio de Isabel de Castilla y Fernando de Aragón, llevaron el título de Príncipes de Asturias los herederos de la Corona de la nueva Monarquía hispánica (Josep Juan Vidal).

Como ha señalado el profesor Jorge de Esteban, es muy destacada «la importancia constitucional que posee la figura de aquel que está llamado a convertirse» en Rey. Tanto es así que «las diferentes Constituciones monárquicas vigentes hoy en Europa, unas más que otras, regulan ciertos aspectos del papel institucional del sucesor", cosa que no sucede —o sólo de manera muy insuficiente- en la actual Constitución Española. El profesor Antonio Torres del Moral, en su excelente y ya clásica monografía sobre el estatuto jurídico del Príncipe de Asturias, nos puso sobre la pista del panorama «desolador» con el que se encuentra cualquier constitucionalista que quiera analizar el - casi inexistenteestatuto del sucesor a la Corona de España. Con análogo criterio, M. FernándezFontecha y A. Pérez de Armiñán subrayan que no puede afirmarse que la Constitución de 1978 configure un status del Príncipe heredero. En efecto, las referencias constitucionales expresas al Príncipe de Asturias se limitan al artículo 57.2 («El Príncipe heredero, desde su nacimiento o desde que se produzca el he- 
cho que origine el llamamiento, tendrá la dignidad de Príncipe de Asturias y los demás títulos vinculados tradicionalmente al sucesor de la Corona de España el Real Decreto 54/1977, de 21 de enero, determinó los títulos y denominaciones que corresponden al heredero de la Corona—), al artículo 59.2 («Si el Rey se inhabilitare para el ejercicio de su autoridad... entrará a ejercer inmediatamente la Regencia el Príncipe heredero de la Corona...») y al artículo 61.2 («El Príncipe heredero, al alcanzar la mayoría de edad,... prestará el mismo juramento - que el que presta el Rey, esto es, de desempeñar fielmente sus funciones, guardar y hacer guardar la Constitución y las leyes, y respetar los derechos de los ciudadanos y de las Comunidades Autónomas-, así como el de fidelidad al Rey»).

Esta falta de regulación constitucional, al menos de los aspectos fundamentales, del status del heredero a la Corona adquiere una especial gravedad si se tiene en cuenta que, cada vez con mayor intensidad — como se encarga de poner de relieve Torres del Moral-, Don Felipe de Borbón lleva a cabo una importante actividad con evidente proyección pública («recibe en audiencia, preside actos, viaja oficialmente y se entrevista con los más altos dignatarios del mundo»). Sin embargo, no sabemos cuáles son las funciones constitucionales del Príncipe de Asturias (salvo en lo relativo a la Regencia), ni qué papel desempeña en sus actuaciones públicas, ni a quién representa en estos casos, ni en calidad de qué preside ciertos actos, ni — y esto es muy importante- quién responde si yerra gravemente en su actuación o en sus intervenciones verbales. Ante tanto silencio, propugnamos una reforma de la Constitución que, sin agotar la materia (cometido que corresponde a la legislación ordinaria), fije los grandes pilares sobre los que deberá sustentarse el estatuto jurídico del sucesor a la Corona.

A nuestro juicio, para regular esta cuestión, sería conveniente, además de tener en cuenta ciertas prácticas ancestrales de la Casa Real española, acudir a las Constituciones monárquicas europeas (añadiendo la del Japón, que asimismo es democrática y parlamentaria), al constitucionalismo histórico español (esencialmente monárquico) y a la, escasa pero muy valiosa, aportación de nuestra doctrina científica. Todo este material nos ofrece un bagaje de propuestas y soluciones que no puede ser ignorado.

\subsection{Deben ampliarse las facultades de las Cortes Generales, para proveer lo que} más convenga a los intereses de España, en el supuesto de que se extinguieran todas las lineas llamadas en Derecho

De acuerdo con el artículo 57.3 CE, «extinguidas todas las líneas llamadas en Derecho, las Cortes Generales proveerán a la sucesión en la Corona en la forma 
que más convenga a los intereses de España». Por tanto, ni siquiera en el hipotético caso de muerte o renuncia de todos los Borbones con derechos hereditarios a la Corona de España, las Cortes podrían optar por la solución republicana, sino que se verían obligadas (como durante el Sexenio Revolucionario, tras la expatriación de Isabel II) a buscar una nueva dinastía por las Cortes europeas, lo que parece bastante alejado de toda lógica y del mínimo sentido común. Es cierto que (superadas, en los países desarrollados, las épocas de las epidemias mortales) este precepto contempla un escenario absolutamente improbable (actualmente, ya son once los Borbones con derechos hereditarios). Sin embargo, las normas, además de su evidente eficacia normativa, también tienen, sin duda, un valor simbólico que no puede despreciarse. Así, proponemos que la reforma de la Constitución suprima del artículo 57.3 la frase «a la sucesión en la Corona», de modo que establezca que, en el caso de inexistencia de sucesor por extinción de todas las líneas llamadas en Derecho, las Cortes Generales «proveerán en la forma que más convenga a los intereses de España», que — a juicio de las mismas - será bien la búsqueda de una nueva dinastía o bien la proclamación de la III República. Con el mismo objetivo, durante los debates constituyentes (concretamente, en la Comisión Constitucional del Congreso), el diputado de Esquerra Republicana de Catalunya Heribert Barrera propuso — infructuosamente — la supresión de todo el párrafo tercero del definitivo artículo 57, al entender que, si se extinguían todas las líneas llamadas a la sucesión, no se debía prejuzgar la forma política futura.

\section{BIBLIOGRAFÍA BÁSICA}

ARAGÓN REYES, Manuel: Dos estudios sobre la Monarquía parlamentaria en la Constitución española, Civitas, Madrid, 1990.

BELDA PÉREZ-PEDRERO, Enrique: El Poder del Rey: alcance constitucional efectivo de las atribuciones de la Corona, Senado, Madrid, 2003.

BURNS MARAÑÓN, Tom: Conversaciones sobre el Rey, Plaza \& Janés, Barcelona, 1995.

CREMADES GARCÍA, Javier: La Casa de S.M. el Rey, Civitas, Madrid, 1998.

FERNÁNDEZ-FONTECHA TORRES, Manuel y PÉREZ DE ARMINNAN Y DE LA SERNA, Alfredo: La Monarquía y la Constitución, Civitas, Madrid, 1987.

FERNÁNDEZ-MIRANDA LOZANA, Pilar y FERNÁNDEZ-MIRANDA CAMPOAMOR, Alfonso: Lo que el Rey me ha pedido. Torcuato Fernández-Miranda y la Reforma Política, Plaza \& Janés, Barcelona, 1995.

FUNDACIÓN INSTITUCIONAL ESPAÑOLA.: La Monarquía española entre las Constituciones de 1876 y 1978, Centro de Estudios Políticos y Constitucionales, Madrid, 1999. 
GARCÍA ABAD, José: La soledad del Rey: ¿está la Monarquía consolidada 25 años después de la Constitución?, La Esfera de los Libros, Madrid, 2004.

GARCÍA CANALES, Mariano: La Monarquía parlamentaria española, Tecnos, Madrid, 1991.

GÓMEZ SÁNCHEZ, Yolanda (coord.): XXV años de Monarquía parlamentaria, Sanz y Torres, Madrid, 2006.

GONZÁLEZ-TREVIJANO, Pedro José: El refrendo, Centro de Estudios Políticos y Constitucionales, Madrid, 1998.

LAFUENTE BALLE, José María: El Rey y las Fuerzas Armadas en la Constitución, Edersa, Madrid, 1987.

LÓPEZ GUERRA, Luis: "Una Monarquía parlamentaria», en el libro colectivo El régimen constitucional español (directores Jorge de Esteban y Luis López Guerra), Labor, Barcelona, 1982, págs. 9-41.

LÓPEZ VILAS, Ramón y NEBREDA PÉREZ, Joaquín María: La dinastía Borbón. La familia real española, Velecio Editores, Madrid, 2004.

LUCAS VERDÚ, Pablo (director): La Corona y la Monarquía parlamentaria en la Constitución de 1978, Universidad Complutense de Madrid, Madrid, 1983.

MARTÍNEZ INGLÉS, Amadeo: Juan Carlos I, el último Borbón. Las mentiras de la monarquía española, Styria, Barcelona, 2008.

MENÉNDEZ REXACH, Ángel: La Jefatura del Estado en el Derecho Público español, INAP, Madrid, 1979.

OLIVER LEÓN, Baldomero: Monarquía y Estado constitucional: la institución monárquica en el proceso de consolidación del Estado constitucional, Tecnos, Madrid, 2002.

OTTO OLIVÁN, Sol: La tutela del Rey menor en la Constitución española de 1978, UNED, Madrid, 2000.

PASCUAL MEDRANO, Amelia: La Regencia en el Derecho Constitucional español, Centro de Estudios Políticos y Constitucionales, Madrid, 1998.

PORRAS RAMÍREZ, José María: Principio democrático y función regia en la Constitución normativa, Tecnos, Madrid, 1995.

RODRÍGUEZ-ZAPATA PÉREZ, Jorge: Sanción, promulgación y publicación de las leyes, Tecnos, Madrid, 1987.

ROLLNERT LIERN, Göran: La Jefatura del Estado. Símbolo e integración política en la Constitución vigente, Minim Edicions, Valencia, 2002.

ROLLNERT LIERN, Göran: El arbitraje y la moderación regios en la Constitución española, Universitat de València, Valencia, 2005.

SÁINZ MORENO, Fernado (coord.): La Monarquía parlamentaria (Título II de la Constitución): VII Jornadas de Derecho Parlamentario, Congreso de los Diputados, Madrid, 2001.

SÁNCHEZ AGESTA, Luis: Los perfiles históricos de la Monarquía constitucional española, Centro de Estudios Constitucionales, Madrid, 1987.

SOLOZÁBAL ECHAVARRÍA, Juan José: La sanción y la promulgación de la ley en la Monarquía parlamentaria, Tecnos, Madrid, 1987. 
TORRES DEL MORAL, Antonio: La Monarquía parlamentaria española, Tecnos, Madrid, 1991.

TORRES DEL MORAL, Antonio: El Principe de Asturias. Su estatuto jurídico, Congreso de los Diputados, Madrid, 2005 (segunda edición, que actualiza la primera de 1997).

TORRES DEL MORAL, Antonio (director): Monarquía y Constitución, Colex, Madrid, 2001, 2 volúmenes (el segundo volumen, dedicado a «Textos Jurídicos», está codirigido por Cristina Rodríguez Coarasa).

TORRES DEL MORAL, Antonio y GÓMEZ SÁNCHEZ, Yolanda (coords.): Estudios sobre la Monarquía, UNED, Madrid, 1995.

TUSSELL, Javier: Juan Carlos I. La restauración de la Monarquía, Temas de Hoy, Madrid, 1995.

VV.AA.: La Corona en la historia constitucional española. Número 55 (monográfico) de la Revista de Estudios Políticos, 1987.

Title

THE CONSTITUTIONAL AMENDMENT OF THE SPANISH CROWN (ONE RADICAL AND TEN MODERATE PROPOSALS).

\section{Summary}

1. THE LEGAL REGIME GOVERNING THE CROWN IN THE 1978 SPANISH CONSTITUTION: AN OVERVIEW: 1.1. The establishment of a monarchy in Spain. 1.2. A parliamentary monarchy as a "political form of Spanish State». 1.3. The King's personal statute. 1.4 Countersignature and unaccountability. 1.5. The King's functions: symbolic, moderatorial and mediatory. 1.6. Succession, regency and guardianship. 1.7. The Royal Household.- 2. THE CONSTITUTIONAL PROCEDURE FOR AMENDING THE CROWN: THE SCOPE AND MEANING OF ARTICLE 168 SC: 2.1. The justifications for constitutional amendments. 2.2. A rigid constitution with two amendment procedures. 2.3. Stages of the special amendment procedure. 2.4. The concealed purpose behind the procedure cited in Article 168 SC: the inclusion of a concealed immutable clause. 2.5. The search for a reasonable solution.- 3. A TOTAL AMENDMENT PROPOSAL: FROM A BOURBON MONARCHY TO A THIRD REPUBLIC: 3.1. A constitution theoretically devoid of immutable clauses. 3.2. A monarchy with constitutional but not democratic support. 3.3. The moral and political superiority of a republic over a monarchy. 3.4. Spain, a parliamentary republic.- 4. TEN PRO- 
POSALS FOR PARTIAL AMENDMENTS. 4.1. The "parliamentary monarchy» must be defined as a «form of government", not a "form of State». 4.2. In the order of succession, the preference for a male as opposed to a female must be eliminated. 4.3. Parliament must be able to disqualify the King permanently from ruling, so that his «immunity» does not become a means of escaping justice. 4.4. Countersignature must extend to the appointment and removal from office of civil and military members of the Royal Household. 4.5. Spending by the King with public money must be controlled. 4.6. Incompatibilities must be established for members of the Royal Family in financial and private affairs. 4.7. The authorship of (and subsequent responsibility for) the King's speeches must be unequivocally established. 4.8. The title and treatment given to the King's wife and Queen's husband must be equalled. 4.9. The basic principles of the legal statute governing the Prince of Asturias must be established. 4.10. The powers of Spanish Parliament must be extended to promote what is most in the interests of the nation in the event of the extinction of the line of succession to the Spanish Crown.- BASIC BIBLIOGRAPHY.

\section{Resumen}

El objeto de este trabajo es analizar la oportunidad y la conveniencia de reformar la Corona (esto es, la Jefatura de Estado monárquica) que consagró la Constitución Española de 1978. Se inicia con una síntesis del actual régimen jurídico de la Corona, exponiendo - a continuación- el procedimiento que debe seguirse para modificarla. Con este objetivo se estudian las fases que prevé el artículo $168 \mathrm{CE}$, que regula el denominado "procedimiento de reforma agravado». Su introducción se debió al deseo de la mayoría conservadora de dar a la Corona una súper protección (a modo de «cláusula de intangibilidad» encubierta), para frenar las preferencias republicanas expresadas por los partidos políticos de izquierdas. Se concluye esta parte del trabajo buscando los resquicios - que existen - para, en su caso, poder llevar a cabo dicha reforma evitando las dificultades extremas que impone el referido artículo 168. Acto seguido, reflexionamos sobre los argumentos que, a nuestro juicio, hacen preferible la República sobre la Monarquía. Éstos, en síntesis, son la mayor calidad democrática de un cargo electivo sobre uno hereditario, la acentuación de la idea de igualdad, la reversibilidad de una designación inadecuada, la cercanía de la figura del Jefe del Estado, la accesibilidad del cargo a todos los ciudadanos y, en definitiva, su racionalidad intrínseca. Por todo ello, propugnamos el tránsito pacífico hacia la Tercera República española; y, para facilitar dicho paso, exponemos, de forma telegráfica y sólo a 
modo de ejemplo orientador, algunos de los elementos básicos del que podría ser el estatuto jurídico de su Presidente. La cuarta y última parte del artículo hace un planteamiento de reforma más modesto. En efecto, contempla la hipótesis de que, por la peculiar transición española de la dictadura a la democracia, todavía se considere necesaria la figura del Rey. Pues bien, entendemos que, en este supuesto, es imprescindible que la Corona se adecue, en lo posible, a los principios democráticos que conforman el régimen político surgido de la Constitución de 1978. Lo que, a nuestro juicio, no ocurre en la actualidad. Para lograr este objetivo, sugerimos — de forma razonada — que se lleven a cabo diez reformas parciales de la Constitución.

\begin{abstract}
The aim of this paper is to analyse the advisability and convenience of amending the Spanish Crown (that is the Monarchal Head of State) established in the 1978 Spanish Constitution. It opens with an overview of the current legal regime governing the Crown, before going on to outline the procedure that must be followed to amend it. With this purpose in mind, an analysis is made of the stages contemplated in Article 168 of the Spanish Constitution, which regulates what is known as the «special amendment procedure». Its incorporation was the result of the conservative majority's desire to give the Crown a super-high level of protection (in the form of a concealed immutable clause) in order to thwart Republican preferences expressed by left-wing political parties. This section of the paper concludes by looking for cracks that might make this amendment process possible, if pertinent, by getting round the heavy obstacles imposed by Article 168. In continuation, the paper reflects on arguments that, in our opinion, make a republic more preferable than a monarchy. In synthesis, they consist of the more democratic nature of an elected post than hereditary succession, the greater idea of equality, the reversibility of an appointment that proves wrong, the less distant figure of an elected head of state, all citizens' potential access to this elected office and, in short, its intrinsic rationality. For all these reasons, we uphold a peaceful changeover to a Third Spanish Republic and, to facilitate this step, in telegraphic form and merely as an example, we outline some of the basic features of a possible legal statute for its President. The fourth and final part of the paper describes a more modest amendment proposal. It contemplates the hypothesis that, given the singular nature of the Spanish transition from a dictatorship to democracy, the figure of a monarch is still necessary. We understand that, in this event, the Crown must be brought into line, as far as possible, with the democratic principles of
\end{abstract}


the political regime derived from the 1978 Constitution, which, in our opinion, is not currently the case. To achieve this objective, we suggest ten carefully reasoned partial amendments to the Constitution.

\section{Palabras clave}

Reforma de la Corona; Monarquía; República; Tercera República española; Procedimientos de reforma constitucional.

\section{Key Words}

Amendments to the Spanish Crown; Monarchy; Republic; Third Spanish Republic; Constitutional amendment procedures. 
